\title{
An internal ligand-bound, metastable state of a leukocyte integrin, $\mathrm{aXB2}$
}

\section{Citation}

Sen, Mehmet, Koichi Yuki, and Timothy A. Springer. 2013. "An internal ligand-bound, metastable state of a leukocyte integrin, aXB2." The Journal of Cell Biology 203 (4): 629-642. doi:10.1083/ jcb.201308083. http://dx.doi.org/10.1083/jcb.201308083.

\section{Published Version}

doi:10.1083/jcb.201308083

\section{Permanent link}

http://nrs.harvard.edu/urn-3:HUL.InstRepos:12406998

\section{Terms of Use}

This article was downloaded from Harvard University's DASH repository, and is made available under the terms and conditions applicable to Other Posted Material, as set forth at http:// nrs.harvard.edu/urn-3:HUL.InstRepos:dash.current.terms-of-use\#LAA

\section{Share Your Story}

The Harvard community has made this article openly available.

Please share how this access benefits you. Submit a story.

Accessibility 


\title{
An internal ligand-bound, metastable state of a leukocyte integrin, $\alpha_{x} \beta_{2}$
}

\author{
Mehmet Sen, ${ }^{1,4,5}$ Koichi Yuki, ${ }^{1,3,4}$ and Timothy A. Springer ${ }^{1,2,4,5}$ \\ IProgram in Cellular and Molecular Medicine, ${ }^{2}$ Department of Medicine, ${ }^{3}$ Department of Anethesiology, ${ }^{4}$ Children's Hospital Boston, and ${ }^{5}$ Department of Biological \\ Chemistry and Molecular Pharmacology, Harvard Medical School, Boston, MA 02115
}

$\mathrm{H}$ ow is massive conformational change in integrins achieved on a rapid timescale? We report crystal structures of a metastable, putative transition state of integrin $\alpha_{x} \beta_{2}$. The $\alpha_{x} \beta_{2}$ ectodomain is bent; however, a lattice contact stabilizes its ligand-binding $\alpha$ ldomain in a high affinity, open conformation. Much of the $\alpha 1 \alpha 7$ helix unwinds, loses contact with the $\alpha$ ldomain, and reshapes to form an internal ligand that binds to the interface between the $\beta$ propeller and $\beta$ I domains. Lift-off of the $\alpha$ l domain above this platform enables a range of extensional and rotational motions without precedent in allosteric machines. Movements of secondary structure elements in the $\beta_{2}$ $\beta I$ domain occur in an order different than in $\beta_{3}$ integrins, showing that integrin $\beta$ subunits can be specialized to assume different intermediate states between closed and open. Mutations demonstrate that the structure trapped here is metastable and can enable rapid equilibration between bent and extended-open integrin conformations and up-regulation of leukocyte adhesiveness.

\section{Introduction}

Integrin $\alpha$ and $\beta$ subunits contain large ectodomains, one transmembrane domain each, and typically short cytoplasmic domains (Fig. 1). The $\alpha$ and $\beta$ subunits come together to form the integrin head, which connects through upper and lower legs in each subunit to the cell membrane. Of 18 integrin $\alpha$ subunits, nine lack and nine contain an $\alpha \mathrm{I}$ domain. In $\alpha \mathrm{I}$-less integrins, ligand binds at the interface between the $\alpha$ subunit $\beta$ propeller and $\beta$ subunit $\beta I$ domains that form the head. $\alpha$ I integrins bind ligand to the $\alpha \mathrm{I}$ domain, which is inserted in the $\beta$ propeller near its interface with the $\beta I$ domain (Luo et al., 2007; Springer and Dustin, 2012).

$\alpha \mathrm{I}$ and $\beta \mathrm{I}$ domains are structurally homologous. They have a metal ion-dependent adhesion site (MIDAS) with a $\mathrm{Mg}^{2+}$ ion that binds an acidic residue in ligands and two states, closed and open. In the open state, a change in configuration in loops around the MIDAS is conveyed to the opposite end of the I domain where it is inserted at its $\mathrm{N}$ - and $\mathrm{C}$-terminal ends in a neighboring domain, the $\alpha$ subunit $\beta$ propeller domain for the $\alpha \mathrm{I}$ domain and the hybrid domain for the $\beta I$ domain (Fig. 1). Allostery is conveyed by the I domain C-terminal $\alpha 7$ helix, which pistons along its axis $\sim 10 \AA$ in the $\mathrm{C}$-terminal direction between the closed and open states (Fig. 1, C-F). Closed and open states have been defined by crystal structures of isolated $\alpha \mathrm{I}$ domains (Lee et al.,

Correspondence to Timothy A. Springer: timothy.springer@childrens.harvard.edu Abbreviations used in this paper: ADMIDAS, adjacent to MIDAS; CR4, complement receptor type 4; MIDAS, metal ion-dependent adhesion site.
1995; Luo et al., 2007). A crystal structure of complement receptor type 4 (CR4; integrin $\alpha_{x} \beta_{2}$ ) revealed a closed $\alpha \mathrm{I}$ domain in the context of an intact $\alpha_{X} \beta_{2}$ ectodomain, which was bent with a closed headpiece and closed $\beta I$ domain (Fig. 1 A; Xie et al., 2010). The $\alpha$ I domain was surprisingly flexible and was visualized in only two of ten different lattice environments, where $\alpha \mathrm{I}$ domain orientation was stabilized by specific lattice contacts.

Integrins exist in three overall conformational states (Luo et al., 2007; Springer and Dustin, 2012): bent with a closed headpiece (Fig. 1 A), extended with a closed headpiece (Fig. 1 C), and extended with an open headpiece (Fig. 1 F). In extension, the knees in the $\alpha$ and $\beta$ subunits assume more obtuse angles, interfaces between the headpiece and lower legs become solvent exposed, and the ligand-binding headpiece extends further above the cell surface and assumes a better orientation for binding ligand on other surfaces (Fig. $1 \mathrm{C}$ ). In headpiece opening, reshaping of the $\beta I$ domain MIDAS near its interface with the $\alpha$ subunit $\beta$ propeller domain is transmitted by $\beta$ I domain $\alpha 7$ helix pistoning to the interface with the hybrid domain, causing the hybrid domain to pivot about its other connection to the $\beta$ I domain and swing out away from the integrin $\alpha$ subunit by $75 \AA$ at the knees (Fig. 1, D and F).

(C) 2013 Sen et al. This article is distributed under the terms of an Attribution-NoncommercialShare Alike-No Mirror Sites license for the first six months after the publication date (see http://www.rupress.org/terms). After six months it is available under a Creative Commons License (Attribution-Noncommercial-Share Alike 3.0 Unported license, as described at http://creativecommons.org/licenses/by-nc-sa/3.0/). 


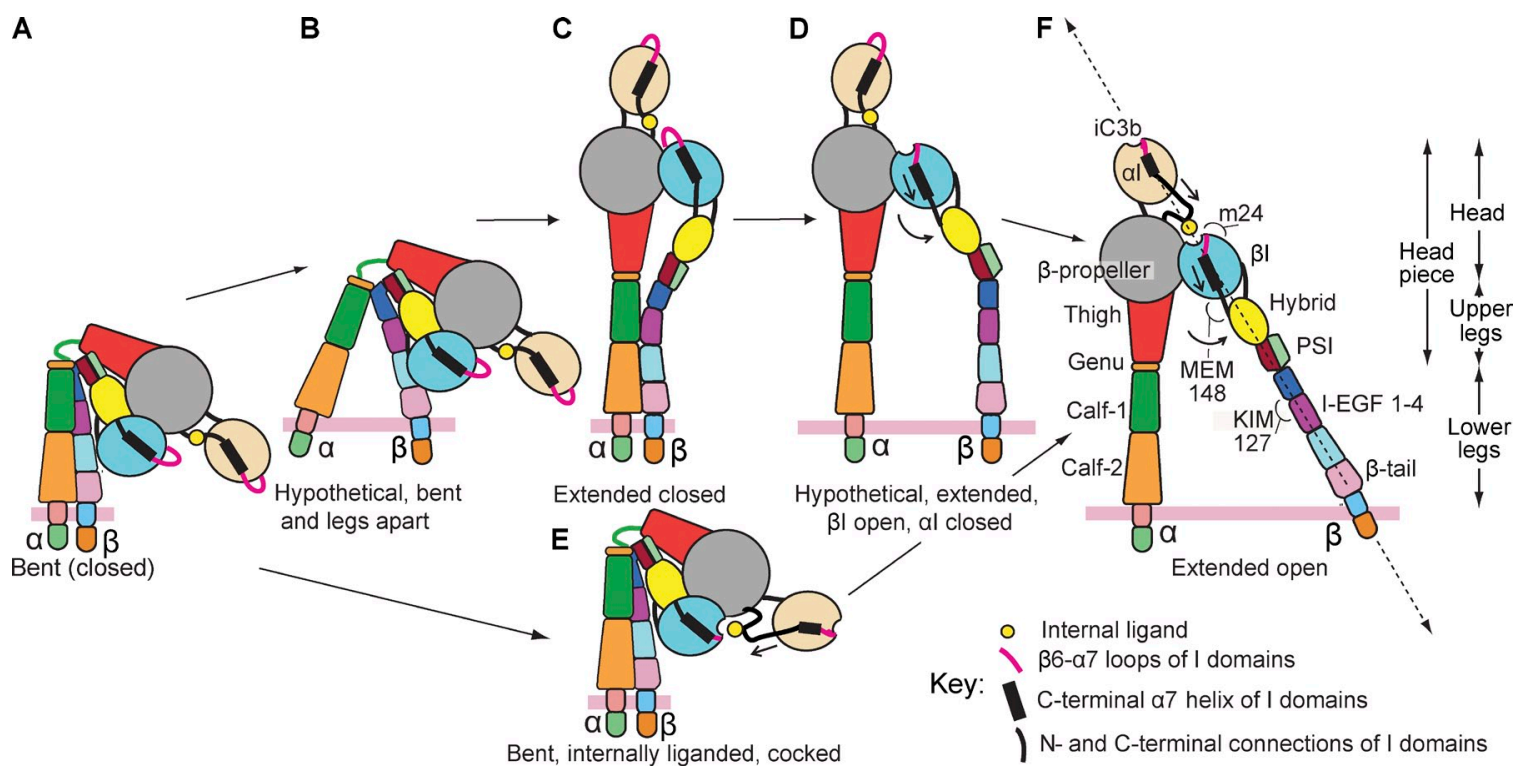

Figure 1. Schematic of $\alpha$ lintegrin activation. All states have been seen in electron microscopy or crystal structures except those marked hypothetical. Locations of Fab and iC $3 b$ binding sites are labeled in F. Forces applied by the actin cytoskeleton on the integrin $\beta$ subunit cytoplasmic domain and resisted by iC $3 \mathrm{~b}$ on an opsonic particle are shown in F as dashed vectors.

Under resting conditions, the $\alpha_{\mathrm{x}} \beta_{2}$ ectodomain is predominantly bent, and in this state the headpiece is closed. The bent and extended, closed conformations have low affinity, whereas the extended, open conformation has high affinity, as demonstrated for both $\alpha_{\mathrm{X}} \beta_{2}$ and $\alpha_{\mathrm{L}} \beta_{2}$ (Chen et al., 2010; Schürpf and Springer, 2011).

Thus, opening of the headpieces of $\alpha_{L} \beta_{2}$ and $\alpha_{X} \beta_{2}$ integrins transmits a signal that increases affinities of their $\alpha$ I domains for ICAM- 1 and iC $3 b$, respectively. It has been proposed that in relay the $\mathrm{C}$-terminal portion of the $\alpha \mathrm{I}$ domain $\alpha 7$ helix and its following $\mathrm{C}$ linker, including an invariant Glu in $\alpha$ I domains, binds to an interface between the $\beta$ propeller and $\beta$ I domains similar to the ligand-binding interface in $\alpha \mathrm{I}$-less integrins (Alonso et al., 2002; Shimaoka et al., 2002). A bell rope-like pull on the $\alpha \mathrm{I} \alpha 7$ helix appears to activate $\alpha \mathrm{I}$ integrins (Yang et al., 2004; Weitz-Schmidt et al., 2011). However, the crystal structure of bent $\alpha_{X} \beta_{2}$ with a closed $\alpha \mathrm{I}$ domain showed that the invariant Glu, $\alpha_{X}$ Glu-318, was quite distant from the $\beta I$ MIDAS, $\sim 16-19 \AA$ away (Xie et al., 2010). How relay is accomplished remains unknown and is currently the most outstanding unanswered question about allostery transmission in integrin extracellular domains.

On cell surfaces, integrins likely exist in dynamic equilibrium between all three states (Fig. 1, A-F), with cellular activation and association with the cytoskeleton and ligand regulating this equilibrium temporally and spatially (Springer and Dustin, 2012). How is transition between the states achieved on a timescale rapid enough to regulate leukocyte adhesiveness in the vasculature (Shamri et al., 2005)? Here we describe internal ligand-bound and cocked conformations of $\beta_{2}$ integrins that may function to accelerate equilibration between the bent-closed and extended-open conformational states and reveal how allostery is relayed between $\alpha \mathrm{I}$ and $\beta \mathrm{I}$ domains. Furthermore, we discover unprecedented extensional and rotational flexibility in an allosteric machine and specialization among integrin $\beta$ subunits in the intermediate states they can assume between closed and open.

\section{Results}

Internal ligand-bound, bent $\alpha_{x} \beta_{2}$ and its crystal lattice

Previous $\alpha_{X} \beta_{2}$ crystals at 3.5-3.95 ̊ resolution with metalchelating salts as precipitants (Xie et al., 2010) lacked metals at the MIDAS and synergistic metal binding site in the $\beta I$ domain (Fig. 2 A). We deleted seven N-linked glycosylation sites and added a disulfide between the membrane-proximal $\alpha_{X}$ calf-2 and $\beta_{2} \beta$-tail domains to obtain greater conformational homogeneity of $\alpha_{X} \beta_{2}$. Crystals in PEG 8000 with $0.2 \mathrm{M}$ magnesium acetate and $0.1 \mathrm{M}$ sodium cacodylate, $\mathrm{pH} 7.2$, revealed metals at all three $\beta \mathrm{I}$ domain sites and diffracted at 2.75 or $2.9 \AA$ resolution (Table 1 and Figs. S1 and S2).

The $\alpha_{X} \beta_{2}$ ectodomain in the new crystal form was bent; surprisingly, the $\alpha \mathrm{I}$ domain was open (Fig. 2, B and E). This open conformation of the $\alpha$ I domain was stabilized by the crystal lattice (Fig. 3). In opening, the $\beta 6-\alpha 7$ loop reshapes as it moves with the pistoning $\alpha 7$ helix (Lee et al., 1995). A lattice contact with the $\alpha$ I domain $\beta 6-\alpha 7$ loop selects the open conformation of this loop; in the closed conformation, the $\beta 6-\alpha 7$ loop would extend upward in the orientation shown in Fig. 3 and severely clash with the lattice. Lattice contacts with the opposite side of the $\alpha \mathrm{I}$ domain hold the $\alpha \mathrm{I}$ domain in a specific position in the crystal lattice (Fig. 3). Meanwhile, other lattice contacts surround the headpiece, upper legs, and lower legs of the $\alpha_{X} \beta_{2}$ ectodomain and stabilize its bent conformation (Fig. 3).

The open $\alpha$ ll domain

The $\alpha \mathrm{I}$ domain in bent, internal ligand-bound $\alpha_{X} \beta_{2}$ has all canonical features of open $\alpha \mathrm{I}$ domains. Compared with closed 

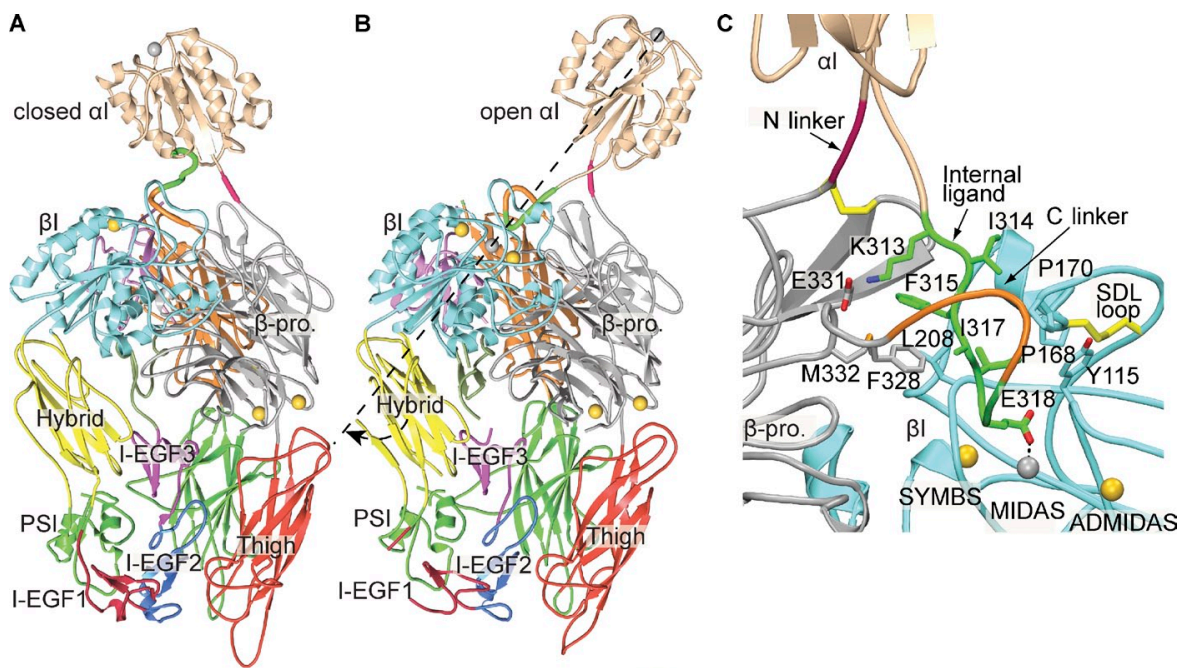

D

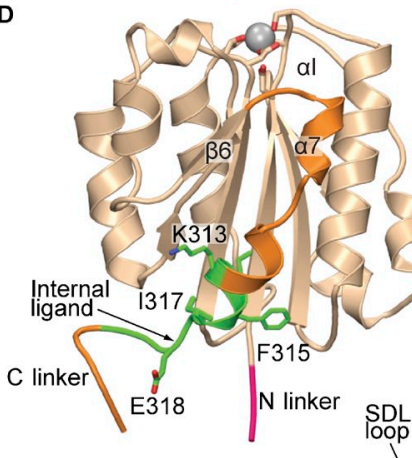

E

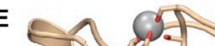

E
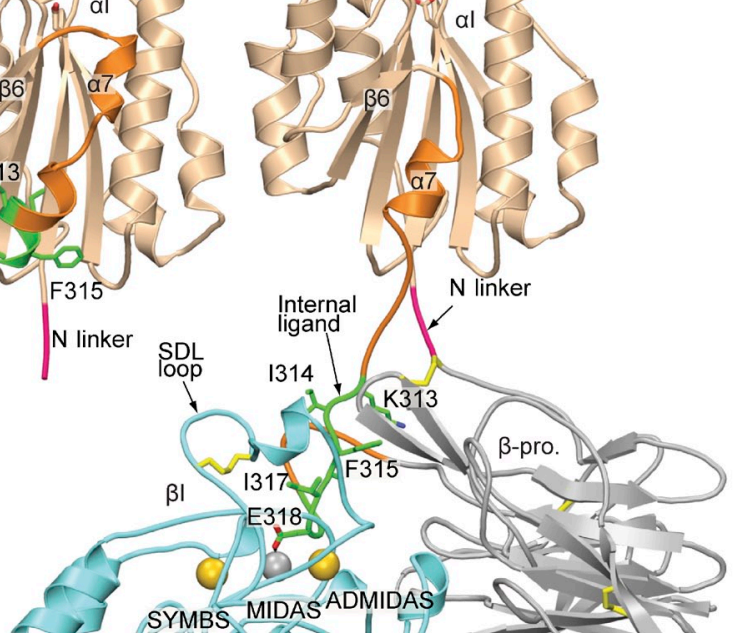

$\alpha$ I domains, the $\mathrm{Mg}^{2+}$ ion at the $\alpha$ I MIDAS moves $2.5 \AA$, breaking and gaining direct coordinations to Asp-240 and Thr-207, respectively (Fig. 4, A and B). Density around the $\alpha$ I MIDAS $\mathrm{Mg}^{2+}$ is strong and includes an additional feature that is modeled as a $\mathrm{Cl}^{-}$ion (Fig. $4 \mathrm{~A}$ ). The $\beta 1-\alpha 1$ loop bearing the MIDAScoordinating DXSXS motif and upper part of the $\alpha 1$ helix shift and the backbone of the $\beta 4-\alpha 5$ loop flips (Fig. 4, A and B). Furthermore, the $\beta 6$ strand tilts relative to $\beta 6$ in closed $\alpha \mathrm{I}$ domains, and the $\beta 6-\alpha 7$ loop moves toward the $C$ terminus with the pistoning $\alpha 7$ helix (Fig. $4 \mathrm{C}$ ).

In contrast, the conformation of the $\alpha 7$ helix of the open $\alpha$ I domain in an intact ectodomain differs markedly from that seen in isolated open $\alpha \mathrm{I}$ domains (Fig. $4 \mathrm{E}$ ). In isolated $\alpha \mathrm{I}$ domains, the $\alpha 7$ helix moves as a unit $10 \AA$ in the $\mathrm{C}$-terminal, axial direction between the closed and open conformations (Fig. 4 D). In internally liganded $\alpha_{\mathrm{X}} \beta_{2}$, the $\alpha \mathrm{I}$ domain $\alpha 7$ helix retains few helical hydrogen bonds and its $\mathrm{C}$-terminal portion is completely unwound (Fig. 4 C). Stretching is spring-like. The distance moved between the closed and internally liganded $\alpha_{X} \beta_{2}$ structures progressively increases from $11 \AA$ at residue 306 to $26 \AA$ at Glu-318 (Fig. 4 C), and the $\alpha 7$ helix elongates to take an overall straight course between the $\alpha \mathrm{I}$ domain and the binding interface that includes the $\beta$ I MIDAS (Fig. 4 E). The open
Figure 2. Overall $\boldsymbol{\alpha}_{\times} \boldsymbol{\beta}_{2}$ structure and the internal ligand. ( $A$ and $B$ ) Cartoon representation of closed ( $A$; $X i e$ et al., 2010) and internally liganded, cocked (B) $\alpha \times \beta_{2}$ structures. (C-E) The $\alpha \mathrm{l}$ domain and internal ligand binding site in the closed (D) and cocked ( $C$ and $E$ ) $\alpha_{x} \beta_{2}$ structures. $D$ and $E$ are after superposition on the $\alpha$ ldomain; only the $\alpha$ ldomain and its linkers are shown in D for clarity. Spheres represent $\mathrm{Ca}$ (gold) and $\mathrm{Mg}^{2+}$ (silver). Disulfides are in yellow. The dashed line in $B$ is drawn through the $\alpha$ and $\beta$ I MIDAS $\mathrm{Mg}^{2+}$ ions, in the same orientation as the dashed line in Fig. $1 \mathrm{~F}$. conformation of the $\alpha \mathrm{I}$ domain and the binding of the internal ligand to the $\beta \mathrm{I}$ domain are associated with a $70^{\circ}$ reorientation of the $\alpha \mathrm{I}$ domain relative to the closed-bent conformation (Fig. 2, A and B; and Fig. S2).

$\alpha$ I domain residues following the $\beta 6-\alpha 7$ loop in the internally liganded $\alpha_{X} \beta_{2}$ ectodomain have a similar local conformation as in the open isolated $\alpha_{M} \alpha I$ domain, but differ in position by a rigid body movement (Fig. 4, G and $\mathrm{H}$ ). These segments are Asn-301 to Leu-308 in $\alpha_{M}$ and Asp-299 to Leu-306 in $\alpha_{X}$. Side chains of $\alpha_{M}$ Asn-301 and $\alpha_{X}$ Asp-299 hydrogen bond to the backbone of the $\mathrm{n}+2$ residue to form an "N-cap" motif that caps the N-terminal end of the $\alpha 7$ helix (Fig. 4, G and H). Previous $\alpha_{\mathrm{M}^{-}}$-isolated $\alpha \mathrm{I}$ structures showed Phe-302 was buried in the closed conformation and surprisingly exposed $\left(156-\AA^{2}\right.$ solventaccessible surface area) in the open conformation (Fig. 4, D and H). In the open $\alpha$ I domain in intact $\alpha_{X} \beta_{2}$, the equivalent Phe-300 packs against the side of the domain (Fig. 4, C and G) and has markedly less exposure $\left(65 \AA^{2}\right)$. In the isolated open $\alpha_{M} \alpha I$ domain, Leu-305 is partially exposed ( $15 \AA^{2}$; Fig. $\left.4 \mathrm{H}\right)$; the relative rotation and tilt of the remnant $\alpha 7$ helix in intact $\alpha_{X} \beta_{2}$ completely bury the equivalent $\alpha_{X}$ residue, Leu-303 ( $0 \AA^{2}$ exposure; Fig. 4 G). As a result, $\alpha_{X}$ residue Leu-303 occupies the position of a nonequivalent open $\alpha_{M}$ residue, Ile-308 (Fig. 4, $\mathrm{G}$ and $\mathrm{H}$ ). 
Table 1. X-Ray diffraction data and structure refinement

\begin{tabular}{|c|c|c|}
\hline Crystal & Native & Dehydrated \\
\hline \multicolumn{3}{|l|}{ Data collection } \\
\hline Space group & $\mathrm{P} 2{ }_{1} 2_{1} 2_{1}$ & $P 2{ }_{1}{ }_{1} 2_{1}$ \\
\hline \multicolumn{3}{|l|}{ Cell dimensions } \\
\hline$a, b, c(\AA)$ & $\begin{array}{c}126.8,131.4 \\
190.2\end{array}$ & $\begin{array}{c}126.9,119.8 \\
182.3\end{array}$ \\
\hline$\alpha, \beta, \gamma\left({ }^{\circ}\right)$ & $90,90,90$ & $90,90,90$ \\
\hline Resolution range $(\AA ̊)$ & $50.0-2.75$ & $50-2.9$ \\
\hline $\mathrm{CC}_{1 / 2}^{\mathrm{b}}$ & $99.7(13.4)^{\mathrm{a}}$ & $98.7(11.8)^{a}$ \\
\hline$R_{\text {merge }}(\%)^{c}$ & $11(305.7)$ & $26.5(449.3)$ \\
\hline $\mathrm{I} / \sigma(I)$ & $10(0.4)$ & $7.96(0.35)$ \\
\hline Completeness (\%) & $98(88)$ & $99.3(99.8)$ \\
\hline Redundancy (\%) & $4.0(3.1)$ & $4.11(4.19)$ \\
\hline Solvent content (\%) & 69 & 65 \\
\hline \multicolumn{3}{|l|}{ Refinement } \\
\hline $\begin{array}{l}\text { Reflections } \\
\text { (total/unique) }\end{array}$ & $328,583 / 81,493$ & $254,780 / 61,864$ \\
\hline$R_{\text {work }} \mathrm{d} / R_{\text {free }}$ e & $0.197 / 0.225$ & $0.231 / 0.264$ \\
\hline $\begin{array}{l}\text { Ramachandran statistics }{ }^{f} \\
\text { (favored/allowed/outliers) }\end{array}$ & $95.9 / 3.8 / 0.3$ & $94.7 / 5.1 / 0.2$ \\
\hline MolProbity score ${ }^{f}(\%)$ & $1.54(100 \%)$ & $1.67(100 \%)$ \\
\hline Clash score $(\%)$ & $4.90(100 \%)$ & $5.8(100 \%)$ \\
\hline \multicolumn{3}{|l|}{ Root mean square deviations } \\
\hline Bond lengths $(\AA ̊)$ & 0.005 & 0.005 \\
\hline Bond angles $\left({ }^{\circ}\right)$ & 0.773 & 0.783 \\
\hline PDB ID no. & $4 \mathrm{NEH}$ & $4 \mathrm{NEN}$ \\
\hline
\end{tabular}

aNumbers in parentheses correspond to the outermost resolution shell. ${ }^{b} \mathrm{CC}_{1 / 2}=$ Pearson's correlation coefficient between average intensities of random half data sets for each unique reflection (Karplus and Diederichs, 2012). ${ }^{c} R_{\text {merge }}=\sum h k\left|\Sigma_{i}\right| l_{i}(h k)-<\bar{I}(h k \mid)|/ \Sigma h k| \Sigma_{i} l_{i}(h k l)$, where $\mathrm{l}_{i}(h k)$ and $\langle\bar{I}(h k)>$ are the $\mathrm{i}$ and mean measurement of the intensity of reflection $\mathrm{hkl}$.

${ }^{\mathrm{d}} R_{\text {work }}=\sum h k \|||$ Fobs $(h k l)|-|$ Fcalc $(h k \|)|| / \sum h k||$ Fobs $(h k l) \mid$, where Fobs $(h k l)$ and $F$ calc $(h k l)$ are the observed and calculated structure factors, respectively. No I/ $\sigma(l)$ cutoff was applied.

${ }^{\mathrm{e}} \mathrm{R}_{\text {free }}$ is the $\mathrm{R}$ value obtained for a test set of reflections consisting of a randomly selected $\sim 5 \%$ subset of the data set excluded from refinement.

fReported by MOLPROBITY (Davis et al., 2007).
The internal ligand

The remarkable elongation of the $\alpha \mathrm{I}$ domain $\alpha 7$ helix is enforced by internal ligand binding. Residues in the $\mathrm{C}$-terminal portion of the $\alpha \mathrm{I} \alpha 7$ helix lose all contact with the $\alpha \mathrm{I}$ domain and completely reshape to form an internal ligand (Fig. 2, C-E; and Fig. S3, A and B). At the tip of a loop formed in the internal ligand, the invariant and mutationally important $\alpha_{X}$ Glu-318 side chain (Huth et al., 2000; Alonso et al., 2002; Yang et al., 2004) coordinates the $\beta I$ MIDAS $\mathrm{Mg}^{2+}$ ion and hydrogen bonds to the backbone of the $\beta I$ I $\beta 1-\alpha 1$ loop (Figs. $2 \mathrm{C}$ and $5 \mathrm{~A}$ ). The strength of these polar interactions is increased by their burial by hydrophobic internal ligand residues $\alpha_{X}$ Ile-314, Phe-315, and Ile-317 (Fig. 2 C). Furthermore, internal ligand residue Lys-313 helps bury Phe-315 and forms a salt bridge to $\beta$ propeller residue Glu-331 (Fig. 5 D). Hydrogen bonds involving Thr-320 secure a type II $\beta$ turn in the internal ligand with Glu-318 at its tip (Fig. 5 E). Another network of hydrogen bonds around Lys-313 and Glu-331 secures the conformation of the segment following the internal ligand, i.e., the $\mathrm{C}$ linker, and residues that form the binding pocket in the $\beta$ propeller domain (Fig. $5 \mathrm{D}$ ). The position of the $\mathrm{C}$ linker completely reshapes during allostery relay (Fig. 2, D and E) and helps to bury the internal ligand (Fig. 2 C). The internal ligand has low B factors and excellent electron density (Fig. S3 A). The dehydrated structure has an identical internal ligand structure and hydrogen bonds, whereas the $\mathrm{C}$ linker differs in conformation at residues 322-324 (Figs. S3 B and S4).

The binding pocket for the internal ligand is formed by hydrophobic residues in the $\alpha_{X} \beta$ propeller and $\beta_{2} \beta I$ domains (Figs. $2 \mathrm{C}$ and $5 \mathrm{~A}$ ). The $\beta \mathrm{I}$ domain contributes MIDAS loop residue Tyr-115, synergistic metal ion binding site residue Leu-208, and Pro-168 and Pro-170 of the disulfide-bonded specificity-determining loop (Figs. $2 \mathrm{C}$ and $5 \mathrm{~A}$ ). The $\beta$ propeller contributes hydrophobic residues Phe-328 and Met-332 (Figs. $2 \mathrm{C}$ and $5 \mathrm{~A}$ ).

The binding pocket for the internal ligand (Fig. $5 \mathrm{~A}$ ) is not unlike that for external ligands in $\alpha \mathrm{I}$-less integrins (Fig. 5, B and C).
Figure 3. Contacts of $\boldsymbol{\alpha}_{\mathbf{x}} \boldsymbol{\beta}_{\mathbf{2}}$ with the crystal lattice. (A) The native structure. (B) The dehydrated structure. The single $\alpha_{\times} \beta_{2}$ molecule in the asymmetric unit is shown as a $\mathrm{C} \alpha$ trace, colored rainbow from beginning of $\alpha$ (blue) to end of $\beta$ (red). Residues of surrounding $\alpha_{x} \beta_{2}$ molecules in the lattice within $4 \AA$ are shown as transparent, solvent-accessible surfaces. The external and internal sides of surfaces are white and black, respectively.
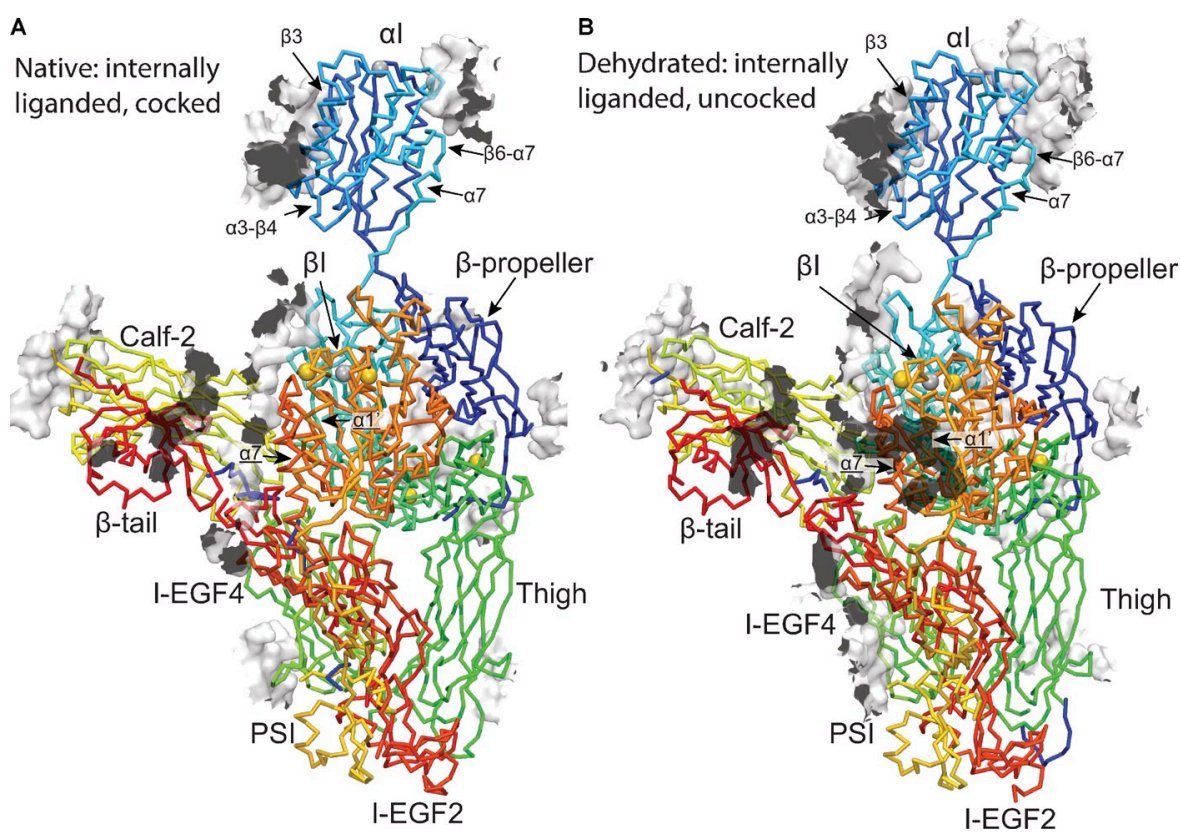
A

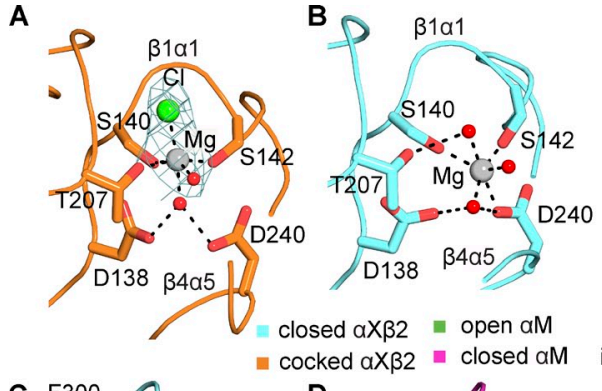

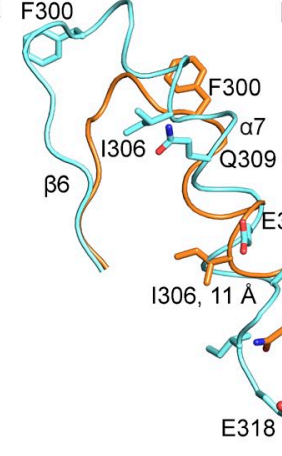

D

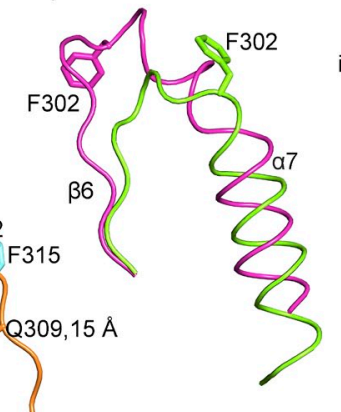

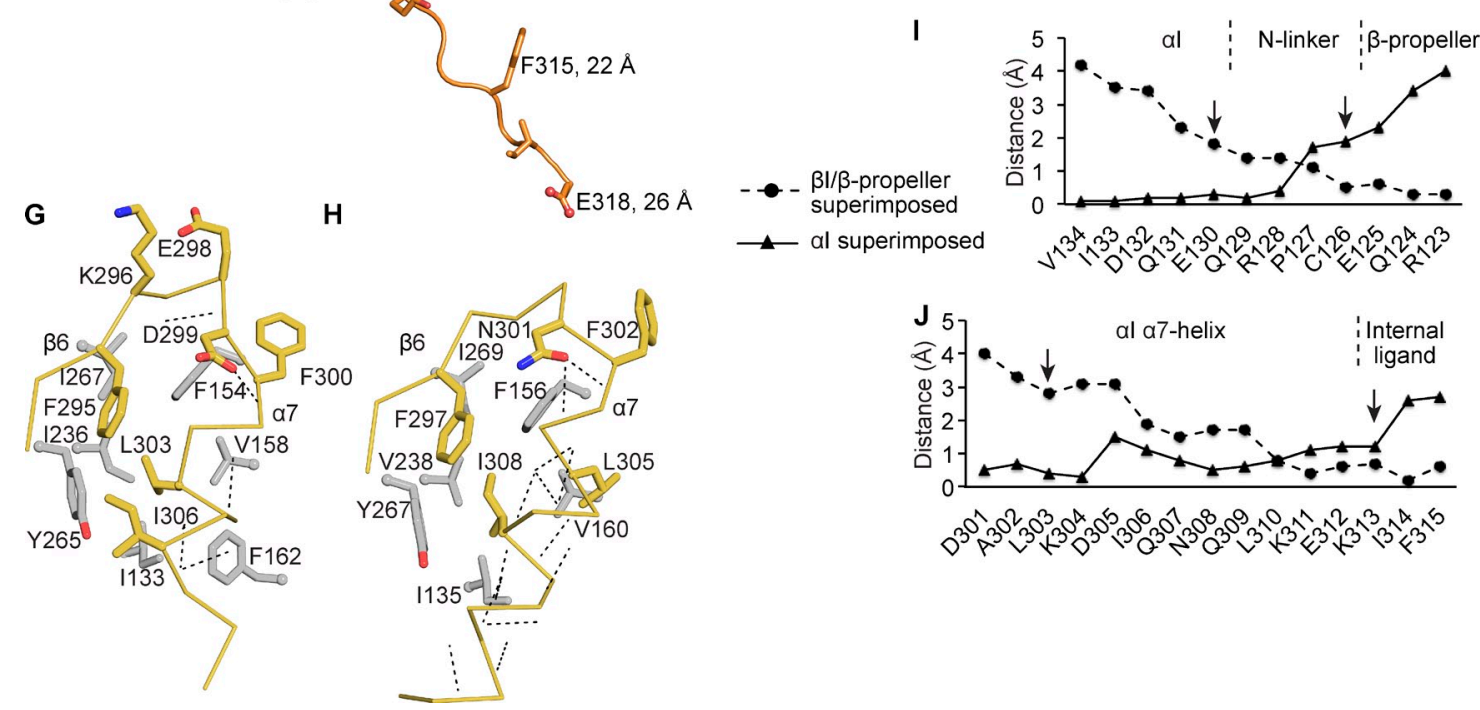

E
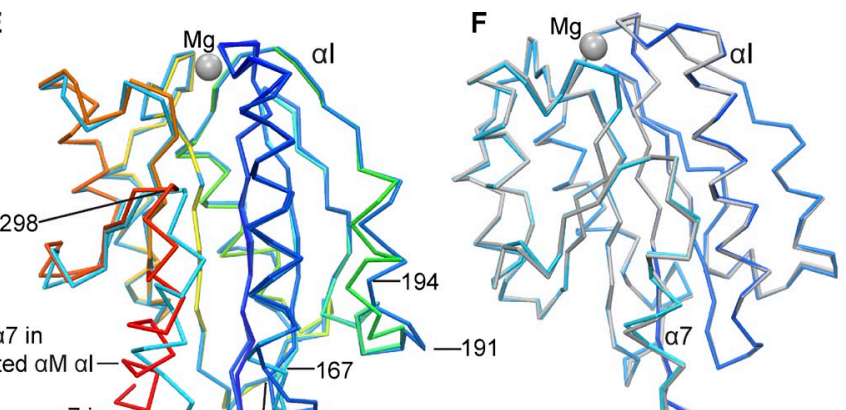

a7 in
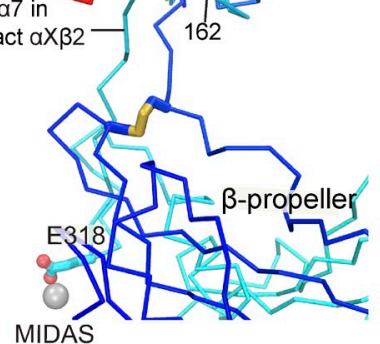

MIDAS

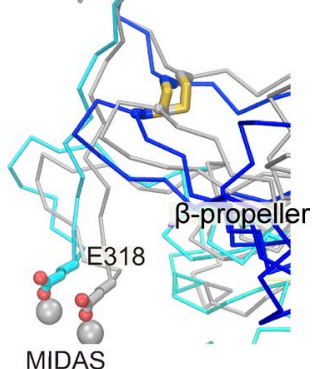

MIDAS

Figure 4. Conformational change in the $\alpha_{x} \alpha$ l domain. (A and B) The open $\alpha$ I MIDAS in internally liganded, cocked $\alpha_{x} \beta_{2}(A)$ and closed $\alpha \mid$ MIDAS in closed $\alpha \times \beta_{2}\left(B_{;}\right.$Xie et al., 2010). $\mathrm{Mg}^{2+}$, water, and $\mathrm{Cl}^{-}$are shown as silver, red, and green spheres, respectively. Mesh in $A$ shows simulated annealing omit map density for the $\mathrm{Mg}^{2+}$ and $\mathrm{Cl}^{-}$ions at $1 \sigma$. (C and D) The $\alpha$ l $\beta 6-\alpha 7$ region of closed and internally liganded, $\operatorname{cocked} \alpha_{x} \beta_{2}(C)$ and isolated $\alpha_{M} \alpha \mathrm{l}$ domains ( $D_{\text {; }}$ Lee et al., 1995) in identical orientations after superposition on $\alpha$ l. Distances in $C$ are between $C \alpha$ atoms of indicated residues in closed and open structures. (E) Superimposed open $\alpha$ l domains in the internally liganded, cocked $\alpha_{x} \beta_{2}$ ectodomain and isolated $\alpha_{M} \alpha$ l domain (Lee et al., 1995). The $\alpha \times \beta_{2}$ ectodomain and isolated $\alpha_{M} \alpha$ l domain are shown as $C \alpha$ traces in rainbow, from blue to red. Their MIDAS Mg ${ }^{2+}$ ions are silver spheres. (F) The native (rainbow colored) and dehydrated (silver) internally liganded $\alpha_{x} \beta_{2}$ structures after superposition on the $\alpha$ l domains. (G and $\left.H\right)$ The $\beta 6-\alpha 7$ loop region of $\alpha_{x} \beta_{2}(G)$ and isolated $\alpha_{M}(H)$ open $\alpha$ l domains, after superposition on the $\alpha$ l domains. $\alpha \alpha$ trace and selected side chains of loop region are shown in wheat. Side chains of nearby hydrophobic residues are shown with silver sticks and small $\mathrm{C} \alpha$ spheres. (I and J) Distances between $\mathrm{C} \alpha$ atoms of two internally liganded structures after superposition on the $\alpha$ l domain (triangles and solid line) or $\beta$ propeller and $\beta I$ domains (circles and dashed line). I and J are aligned so that the linkers run in the same direction and residues at closest approach are aligned (128 with 310$)$.

The closest resemblance is to $\alpha_{4} \beta_{7}$. $\beta_{7}$ Leu-236 is in the same position as $\beta_{2}$ Leu-208, and $\beta_{7}$ Leu-236 interacts with the phenylalanine-like moiety of an antagonist similarly to how $\beta_{2}$ Leu-208 interacts with internal ligand residue $\alpha_{X}$ I317 (Fig. 5, $\mathrm{A}$ and $\mathrm{B}$, arrows). Interestingly, similar phenylalanine-based antagonists of $\beta_{2}$ integrins block relay between the $\alpha \mathrm{I}$ and $\beta \mathrm{I}$ domains, and binding of these antagonists to $\beta_{2}$ integrins requires the $\beta$ I MIDAS and not the $\alpha$ I domain (Shimaoka et al., 2003a).

Structurally important hydrophobic internal ligand and binding pocket residues equivalent to $\alpha_{\mathrm{X}}$ Ile-314, Phe-315,
Ile-317, Phe-328, and Met-332 are invariantly conserved in all nine $\alpha \mathrm{I}$ integrin subunits (Fig. 5 F). Also conserved are Gly-319 and Thr-320, which stabilize the $\beta$ turn at Glu-318, and Lys-313 and Glu-331, which interact and nucleate many hydrogen bonds at the $\mathrm{C}$ linker (Fig. $5 \mathrm{~F}$ ). These findings suggest that the relay mechanism visualized here in $\alpha_{\mathrm{X}} \beta_{2}$ will be general for all $\alpha \mathrm{I}$ integrins.

A cocked $\beta$ I domain

Binding to the internal ligand induces "cocking" of the $\beta I$ domain (Fig. 6 A). The adjacent to MIDAS (ADMIDAS) metal 
Figure 5. The internal ligand and its binding site. $(A-C)$ Internal and external ligand binding sites, in identical orientations after superposition on $\beta$ propeller and $\beta \mid$ domains. Structures for $\alpha_{4} \beta_{7}$ (Yu et al., 2012) and $\alpha_{\| 11} \beta_{3}$ (Springer et al., 2008) use PDB ID numbers 3V4V and 2VDR, respectively. ( $D$ and $E$ ) Hydrogen bond networks around the $\alpha$ and $\beta$ propeller proximal ends of the internal ligand and $C$ linker (D) and in the $\beta$ turn in the internal ligand (E). (F) Sequences of all human $\alpha$ integrins around the internal ligand. Dots mark decadal residues in $\alpha x$.

\author{
A $\alpha \times \beta 2$
}

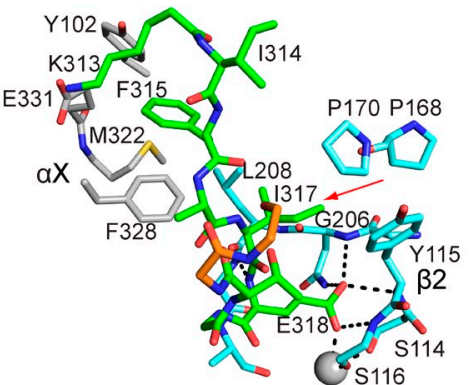

D

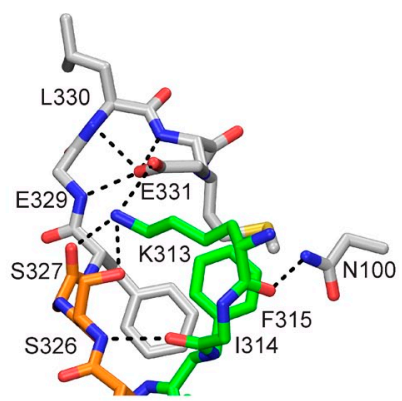

B $\alpha 4 \beta 7$

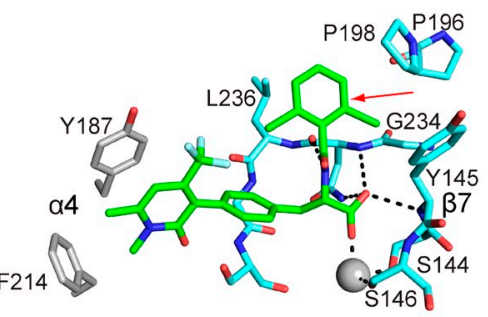

E
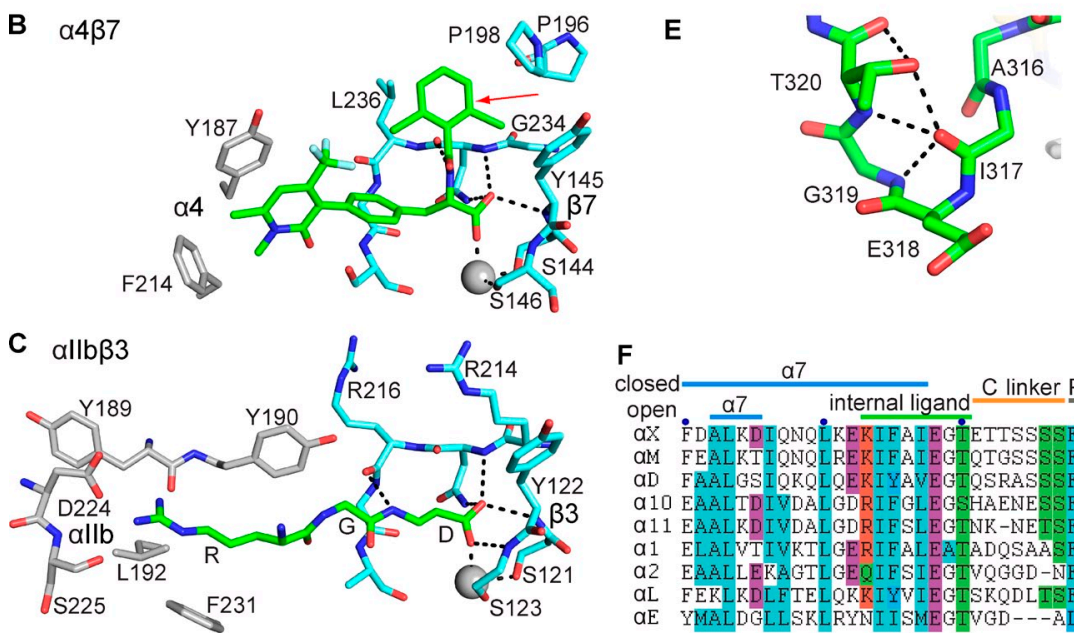

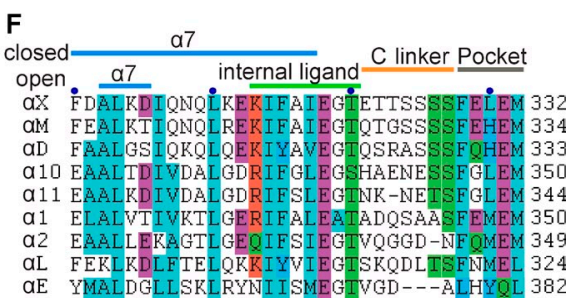

ion, $\beta 1-\alpha 1$ loop, $\alpha 1$ helix, and $\alpha 1^{\prime}$ helix of the $\beta$ I domain all move toward the internal ligand Glu-318 side chain, enabling it to form multiple hydrogen bonds to the $\beta 1-\alpha 1$ loop backbone (Figs. $5 \mathrm{~A}$ and $6 \mathrm{~A}$ ). Electron density for the $\beta \mathrm{I} \alpha 1$ helix and $\alpha 1^{\prime}$ helix is excellent in both native and dehydrated crystal structures (Fig. S3, C and D).

Val-124, Leu-127, Leu-131, Leu-135, and I-138 are hydrophobic residues that anchor the $\alpha 1$ and $\alpha 1^{\prime}$ helices in their groove; they all move toward the $\beta$ I MIDAS in the cocked conformation (Fig. 6 A). Of these, Val-124 and Leu-127 alternately occupy a single hydrophobic ratchet pocket in the cocked conformation. Val-124 is buried in the ratchet pocket in closed $\beta I$ and partially exposed in cocked $\beta$ I (Fig. 6 A). In contrast, Leu127 is substantially solvent exposed in the closed structure and becomes buried in the cocked structure in the ratchet pocket vacated by Val-124 (Fig. 6 A). Movement of Leu-127 into the ratchet pocket is also associated with nearby backbone movements in the $\alpha 1-\alpha 1^{\prime}$ loop that shorten $\alpha 1$ and lengthen $\alpha 1^{\prime}$.

The $\alpha 1$ and $\alpha 1^{\prime}$ helix displacements in the cocked $\beta_{2}$ structure are greater than in $\beta_{1}$ and intermediate conformations
A $\operatorname{ax\beta 2}$ (cocked)

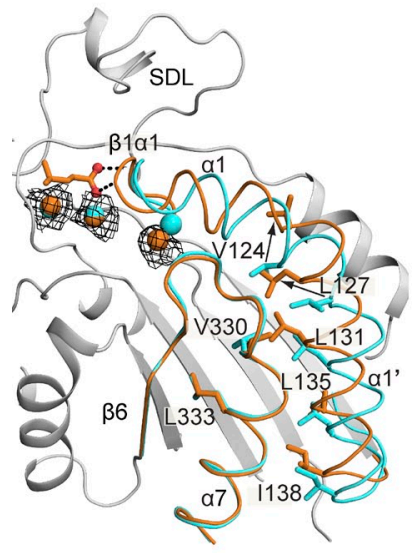

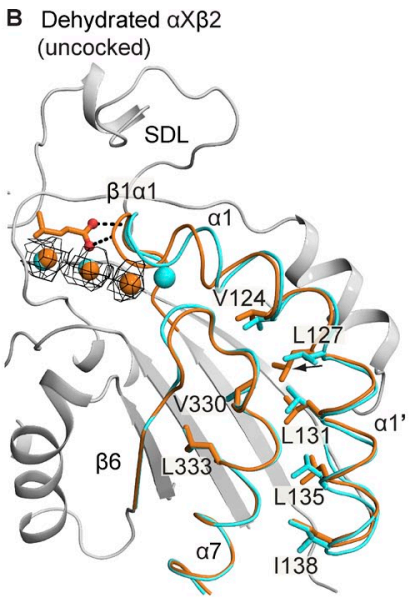

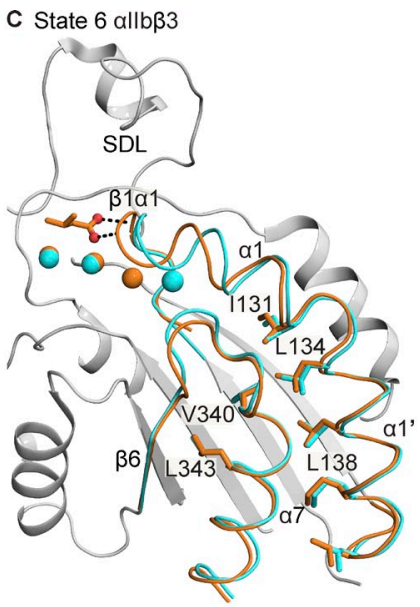

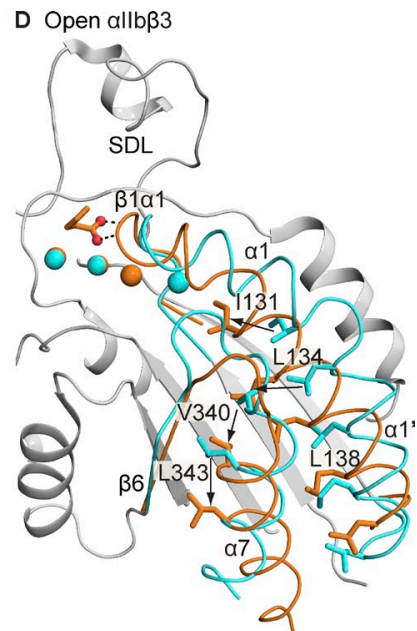

Figure 6. The cocked and uncocked $\boldsymbol{\beta}_{2} \boldsymbol{\beta}$ I domain conformations. Internally liganded, cocked $\beta_{2}(A)$, internally liganded, uncocked $\beta_{2}(B)$, intermediate state $6 \beta_{3}\left(C\right.$; Zhu et al., 2013), and open $\beta_{3}$ (D; Xiao et al., 2004) $\beta$ l domains (gold) are superimposed on closed counterparts (cyan). Structurally similar regions are gray and the ligand Asp or Glu residue and hydrogen bonds (dashed) to the $\beta 1-\alpha 1$ loop are shown. Mesh shows $2 \sigma 2$ Fo-Fc density on the internally liganded $\beta_{2} \beta \mid$ metal ions. 
Table 2. Displacements from closed $\boldsymbol{\beta}$ I domains

\begin{tabular}{lccc}
\hline Conformation & \multicolumn{3}{c}{ C $\boldsymbol{\alpha}$ root mean square deviation } \\
\cline { 2 - 4 } & $\boldsymbol{\beta} \mathbf{1 - \boldsymbol { \alpha }}$ 1 loop & $\boldsymbol{\alpha}$ 1 helix & $\boldsymbol{\alpha} \mathbf{1}^{\prime}$ ' helix \\
\hline & $\AA$ & $\AA$ & $\AA$ \\
Cocked $\beta 2$ & 1.5 & 2.4 & 2.9 \\
Uncocked $\beta 2$ & 1.2 & 0.9 & 0.6 \\
Intermediate $\beta$ 1 & 1.3 & 0.7 & 0.2 \\
Intermediate $\beta 3$ & 1.9 & 1.5 & 1.5 \\
Intermediate state 6 $\beta 3$ & 1.6 & 0.8 & 0.4 \\
Intermediate state 7 $\beta 3$ & 1.6 & 3.5 & 1.3 \\
Final state 8 $\beta 3$ & 2.1 & 4.4 & 3.8 \\
Open $\beta 3$ & 2.1 & 4.3 & 4.0 \\
\hline
\end{tabular}

$\beta 1, \beta 2$, and $\beta 3 \beta 1$ domains were superimposed on their closed counterparts. Differences in position were determined for $\beta 2$ residues $Y 115-M 117[\beta]-\alpha]$ loop), D120-V124 ( $\alpha 1$ helix), and G128-1138 ( $\alpha 1$ ' helix) and their equivalents in other $\beta$ subunits. Structures use the following PDB ID numbers: intermediate $\beta$ $(3 \mathrm{~V} \mid 4)$ and its closed counterpart $(3 \mathrm{~V} / 3)$; intermediate $\beta_{3}(1 \mathrm{~L} 5 \mathrm{G})$ and its closed counterpart (1JV2); $\beta_{3}$ intermediate state 6 (3ZE2; chain B), state 7 (3ZDZ; chain $B)$, final state 8 (3ZE2; chain D), and open $\beta_{3}(2 \mathrm{VDR})$ and their closed counterpart (3T3P).

2-6 of $\beta_{3}$ integrins obtained after soaking Arg-Gly-Asp mimetics into crystals (Fig. 6 C and Table 2; Xiong et al., 2002; Nagae et al., 2012; Zhu et al., 2013). Furthermore, homologous $\alpha 1$ and $\alpha 1^{\prime}$ helix hydrophobic residues are buried in closed conformations of $\beta_{1}$ and $\beta_{3}$ integrins and remain so in intermediate and open conformations (Fig. 6, C and D). As the $\alpha 1$ and $\alpha 1^{\prime}$ helices join in a single helix in the open state of the $\beta_{3}$ subunit, $\beta_{3}$ residue Leu-134 moves laterally to occupy a ratchet pocket that is vacated by gatekeeper residue Val-340 in the $\beta 6-\alpha 7$ loop (Fig. 6 D). The semiexposure of homologous $\beta_{2}$ residue Leu127 in the closed state enables it to vault over gatekeeper residue Val-330, achieving substantial $\alpha 1$ and $\alpha 1^{\prime}$ helix movement without $\beta 6-\alpha 7$ loop movement in cocked $\alpha_{X} \beta_{2}$ (Fig. 6 A).

\section{An uncocked $\beta$ I domain}

Remarkably, dehydration of the $\alpha_{X} \beta_{2}$ crystal reversed cocking. A lattice contact with the $\beta$ I domain $\alpha 7$ helix inhibits its pistoning and with other lattice contacts prevents swing-out of the hybrid domain (Fig. 3). As the solvent content of crystals decreased from 69 to $64 \%$ during dehydration, the lattice contact with the $\alpha 7$ helix expanded to include the adjacent $\alpha 1^{\prime}$ helix (Fig. 3 B). The dehydrated crystal lattice is incompatible with the position of the cocked $\alpha 1^{\prime}$ helix in the native crystal. Therefore, it appears that the growth of lattice contacts caused the $\alpha 1^{\prime}$ helix and in turn the $\alpha 1$ helix to move back toward their positions in the closed conformation and assume a position we term uncocked (Fig. 6 B). Notably, in their cocked positions the $\beta I$ domain $\alpha 1$ and $\alpha 1^{\prime}$ helices have no significant lattice contacts in the native crystal (Fig. $3 \mathrm{~A}$ ); thus it appears that cocking in the native crystal is a closer approximation of changes that occur in the $\beta$ I domain in response to internal ligand binding.

These results demonstrate that cocking is not necessary for internal ligand binding. The conformation of the internal ligand is essentially identical in the two crystal forms (Fig. S4), and neither the internal ligand nor the wound or unwound portions of the $\alpha \mathrm{I}$ domain $\alpha 7$ helix have lattice contacts in the native crystal (Fig. $3 \mathrm{~A}$ ). Therefore, the energetics of internal ligand binding are sufficient to drive $\alpha 7$ helix unwinding in the absence of cocking. Compared with its position in closed $\beta_{2}$, the $\beta$ I domain $\beta 1-\alpha 1$ loop moves significantly toward $\alpha_{X}$ Glu-318 in both the native and dehydrated structures, and the ADMIDAS metal ion moves even more in the dehydrated than native structure (Fig. 6, A and B). Thus, $\beta$ I domain $\beta 1-\alpha 1$ loop movement and ADMIDAS movement are closely associated with internal ligand binding. Cocking appears to be a normal consequence of, but is not required for, internal ligand binding.

\section{Mutational evidence for metastability}

We tested with mutations the functional relevance of the internal ligand and the hypothesis that the internally liganded state and the cocked state are metastable intermediates in the process of integrin activation on cell surfaces. CR4 function was measured using rosetting with iC3b-sensitized erythrocytes (Fig. 7 A), which has previously been shown to require the open headpiece conformation of $\alpha_{X} \beta_{2}$ with hybrid domain swing-out (Chen et al., 2010). We also measured the effect of mutations on activation epitope exposure. Binding of KIM127 antibody to a $\beta$ leg epitope has been shown to require extension (Nishida et al., 2006), and binding of m24 and MEM148 antibodies to $\beta \mathrm{I}$ and hybrid domain epitopes has been shown to measure headpiece opening (epitopes are marked in Fig. 1 F; Chen et al., 2010).

Internal ligand substitutions $\alpha_{\mathrm{X}}$ K313I, F315E, and I317H, predicted to destabilize internal ligand binding and hence allostery relay, all abolished $\mathrm{Mn}^{2+}$-dependent rosetting (Fig. 7, A and B). Mutation of Glu-318 to Ala, Lys, or Met abolished rosetting and mutation to Asp greatly diminished rosetting (Fig. 7 B). Disfavoring the type II $\beta$ turn at Gly-319 by mutation to Pro diminished rosetting (Fig. 7 B). Internal ligand substitutions were also inhibitory using $\alpha_{X} \beta_{2}$ activated by replacement of the human $\beta_{2}$ subunit with chicken $\beta_{2}$ (Fig. 7 C; Bilsland et al., 1994). These results establish the physiological importance of internal ligand residues to $\mathrm{iC} 3 \mathrm{~b}$ rosetting. The same mutations abolished, or diminished in the case of G319P, $\mathrm{Mn}^{2+}$-dependent exposure of the KIM127 epitope (Fig. 7 D), demonstrating that on cell surfaces binding of the internal ligand to its pocket is required for and associated with extension of $\alpha_{X} \beta_{2}$. Mutation of the same residues also diminished, but to a lesser extent, $\mathrm{Mn}^{2+}$-dependent exposure of $\mathrm{m} 24$ and MEM148 epitopes (Fig. 7, E and F). Thus, allostery relay is also associated with headpiece opening on cell surfaces.

If an open $\alpha$ I domain associated with a bent ectodomain is metastable, then substitutions designed to stabilize the internal ligand-bound, open $\alpha$ I conformation should stabilize extension and headpiece opening rather than the bent, closed headpiece conformation crystallized here. $\alpha_{\mathrm{X}} \alpha \mathrm{I}$ domain residues F300, I306, and I314 are more buried in the $\beta 6-\alpha 7$ loop and $\alpha 7$ helix in bent, closed $\alpha_{X} \beta_{2}$ than in bent, cocked $\alpha_{X} \beta_{2}$. Mutations of these residues induced iC 3b rosetting (Fig. 7, A and B), $\alpha_{X} \beta_{2}$ integrin extension (Fig. 7 D), and headpiece opening in $\mathrm{Mg}^{2+}$ / $\mathrm{Ca}^{2+}$ (Fig. 7, E and F). These findings suggest that the open $\alpha \mathrm{I}$ domain on cell surfaces is normally associated with the extended, open headpiece rather than the bent, closed conformation of $\alpha_{X} \beta_{2}$. In summary, these mutations were designed to stabilize internally liganded, bent $\alpha_{X} \beta_{2}$ with a closed headpiece 
A

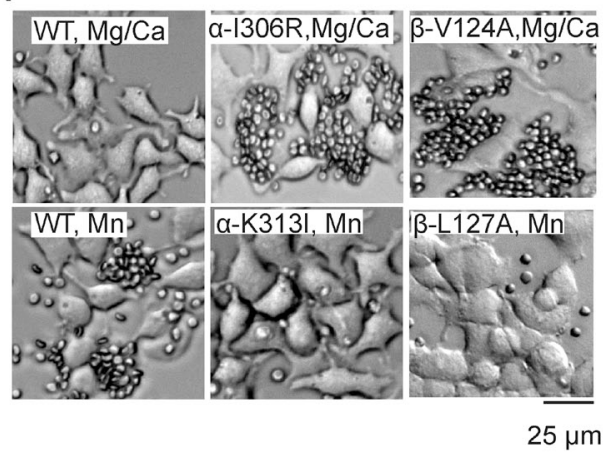

B

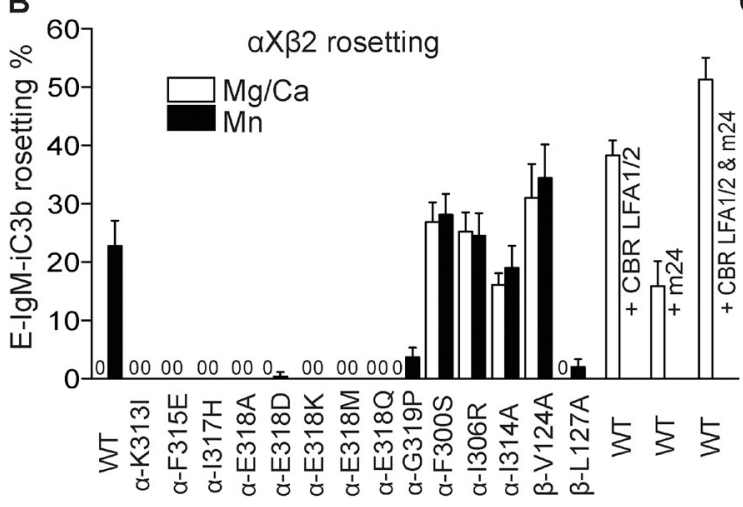

C

aXß2 rosetting (Chicken $\beta 2$ )

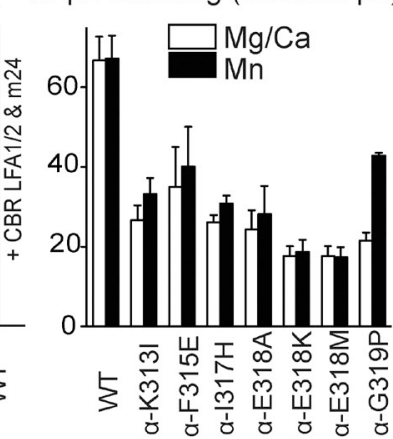

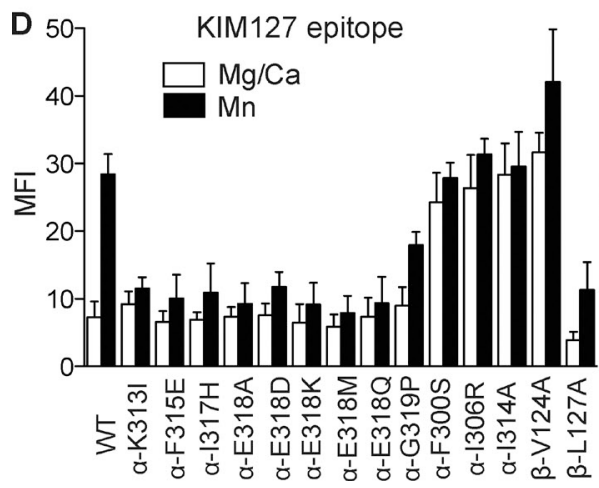
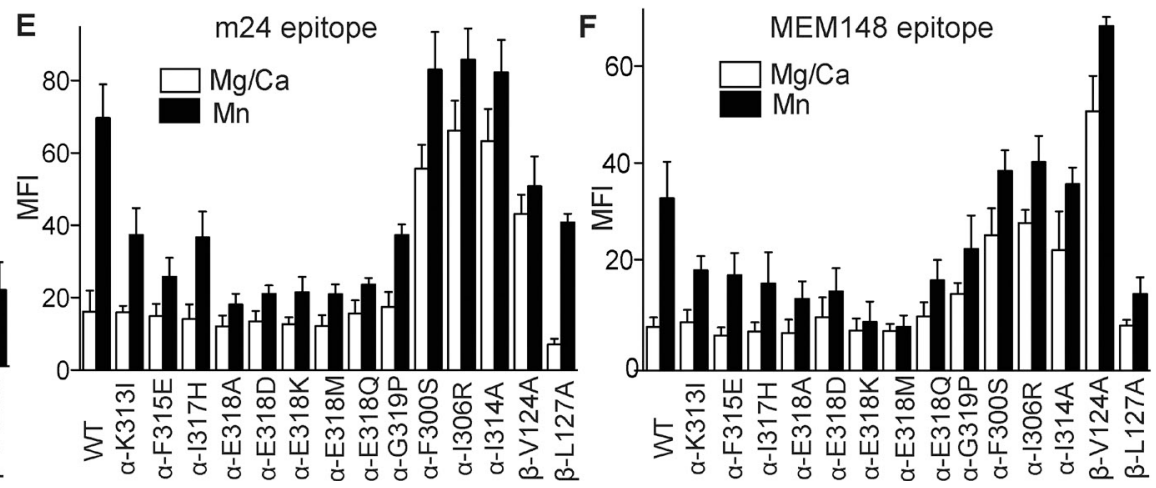

Figure 7. iC3b rosetting and epitope exposure by $\boldsymbol{\alpha}_{\mathbf{x}} \boldsymbol{\beta}_{2}$ with conformation-selective mutations. (A) Representative photomicrographs of E-IgM-iC3b erythrocyte binding to $\alpha_{x} \beta_{2}$ 293T cell transfectants (larger cells). (B and C) Human $\alpha_{x} \beta_{2}$ (B) and human $\alpha_{x} /$ chicken $\beta_{2}$ (C) transfectants rosetting with $\geq 10$ E-IgM-iC3b. (D-F) Epitope exposure measured by mean fluorescent intensity (MFI) of antibody straining of 293T transfectants.

and an open $\alpha \mathrm{I}$ domain, yet stabilized extension and an open headpiece, demonstrating metastability.

The metastability of the cocked state of the $\beta I$ domain was independently examined by mutating $\beta I$ domain ratchet residues implicated in cocking. In cocking, Leu-127 displaces Val-124 from the ratchet pocket and Val-124 becomes partially solvent exposed; therefore, mutation of Val-124 to Ala should stabilize the cocked conformation. However, V124A mutant $\alpha_{X} \beta_{2}$ did not remain bent because in $\mathrm{Mg}^{2+} / \mathrm{Ca}^{2+}$ the KIM127 epitope in the $\beta_{2}$ leg became exposed, demonstrating extension (Fig. 7 D). Furthermore, V124A mutation induced m24 and MEM148 epitope exposure (Fig. 7, E and F). MEM148 binds far from the $\alpha 1$ and $\alpha 1^{\prime}$ helices, to the inner face of the $\beta I$-hybrid interface (Fig. 1 F), and demonstrates that the V124A mutation induces hybrid domain swing-out. Moreover, V124A mutation strongly activated ligand binding by $\alpha_{\mathrm{X}} \beta_{2}$ in $\mathrm{Mg}^{2+} / \mathrm{Ca}^{2+}$ (Fig. 7 B). These findings demonstrate that the cocked conformation of the $\beta I$ domain is metastable; stabilizing cocking induces on cell surfaces the extended-open headpiece conformation rather than the bent, closed headpiece conformation seen here in crystals. The other ratchet residue, Leu-127, is buried in the pocket in the cocked conformation and partially exposed in the closed conformation; therefore, the L127A mutation should inhibit cocking. L127A mutation inhibited $\mathrm{Mn}^{2+}$-stimulated CR4 function and KIM127, m24, and MEM148 exposure (Fig. 7). These results are consistent with the cocked conformation of the $\beta I$ domain resembling, and being on pathway to, the active, high affinity state of $\alpha_{X} \beta_{2}$. Thus, although lattice contacts with the $\alpha$ I domain stabilize its open conformation, other lattice contacts with the body of the ectodomain stabilize the bent conformation with a swung-in hybrid domain.

\section{Discussion}

We have described a novel bent, internally liganded conformation of integrin $\alpha_{X} \beta_{2}$ with an open $\alpha$ I domain. Internal ligand binding induced a cocked conformation of the $\beta$ I domain; however, internal ligand binding did not require cocking. The protein construct differed from one that previously yielded crystals of a bent $\alpha_{X} \beta_{2}$ ectodomain with a closed $\alpha$ I domain (Xie et al., 2010). However, the removal of seven N-linked glycosylation sites and introduction of a C-terminal disulfide are unrelated to internal ligand binding and cocking; instead, the open conformation of the $\alpha \mathrm{I}$ domain is stabilized by a crystal lattice contact with the $\alpha$ I domain $\beta 6-\alpha 7$ loop.

The internal ligand-bound, cocked and internal ligandbound, uncocked states seen here appear to be at local energy minima between the bent-closed and the extended-open conformations. However, they are metastable in the sense that they may be higher energy than either the bent-closed or extendedopen conformations and thus not at a global energy minimum. A precedent for stabilization by a crystal lattice of two alternative conformational states comes from integrin $\alpha_{M} \beta_{2}$, i.e., CR3. $\alpha_{M} \beta_{2}$ and $\alpha_{X} \beta_{2}$ are sister integrins with unusually high sequence identity among $\alpha$ subunits (60\%; Yu et al., 2012). The isolated $\alpha_{M} \alpha \mathrm{I}$ domain was found to be in the closed conformation in 
A
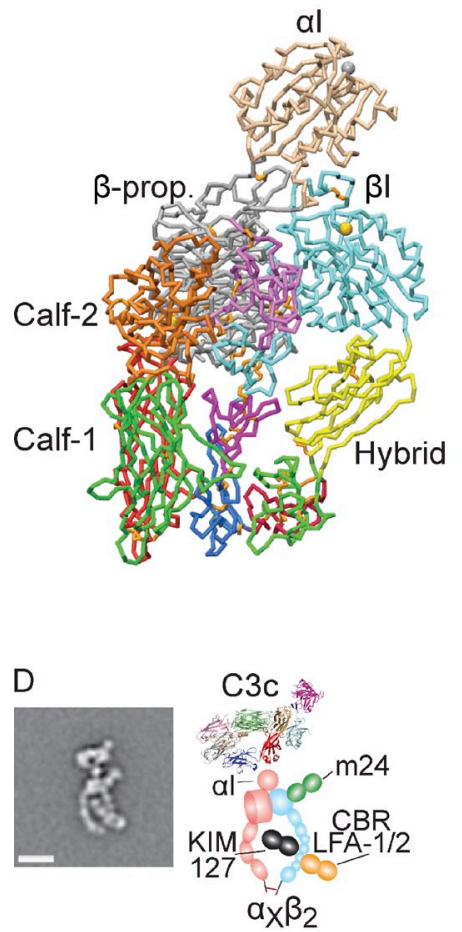

B
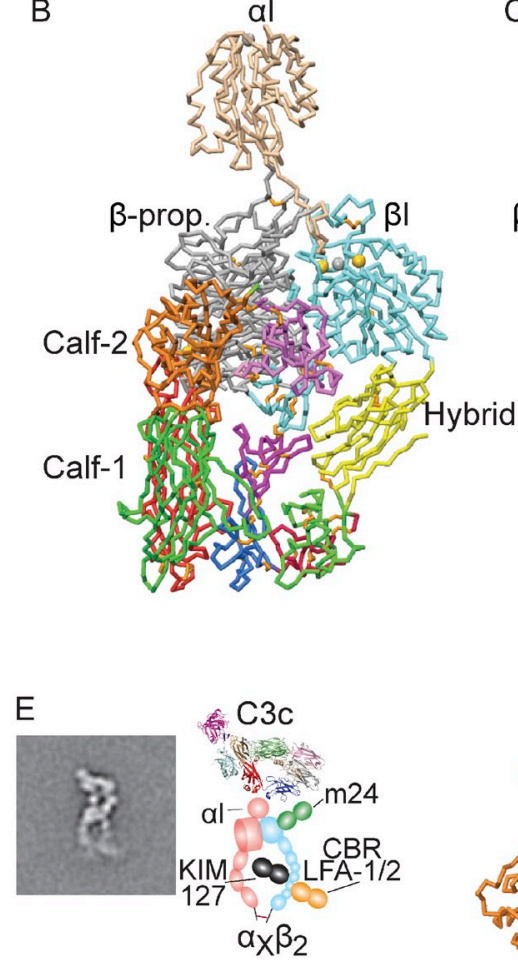

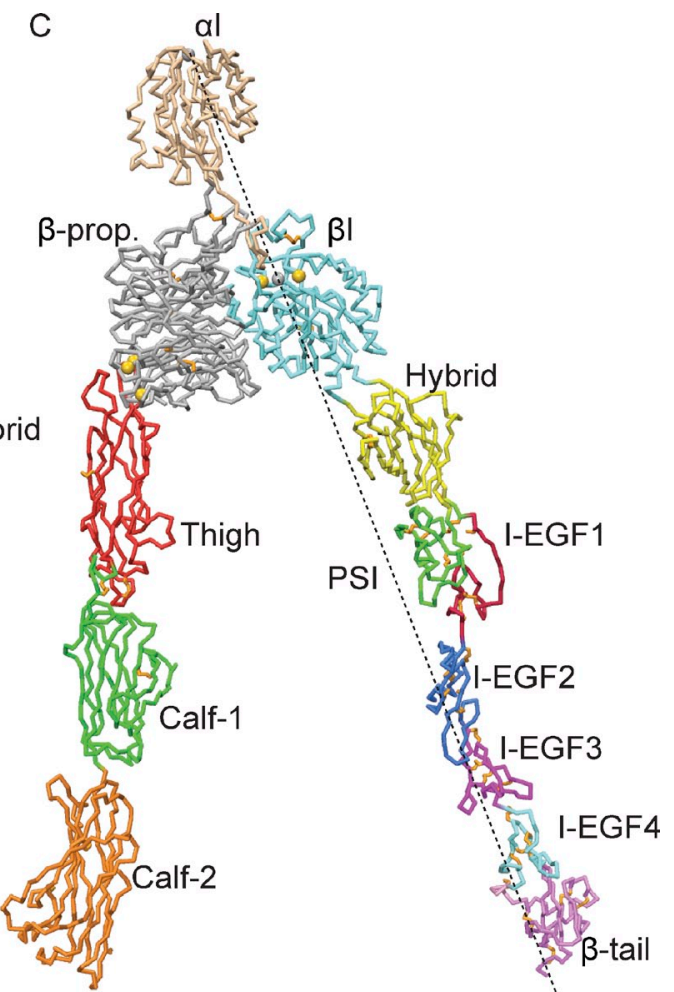

Figure 8. $\quad \boldsymbol{\alpha}_{\mathbf{x}} \boldsymbol{\beta}_{2}$ conformations. Bent (A) and internally liganded (B) $\alpha_{x} \beta_{2}$ crystal structures and an extended-open model (C). The extended-open model is built from cocked $\alpha_{x} \beta_{2}$ by superimposition on the open $\alpha_{\| b} \beta_{3}$ headpiece to obtain its $\beta$ l hybrid domain orientation (chain F; PDB ID number $3 F C U$ [Zhu et al., 2008]) and reorientation at the thigh-calf-1 and I-EGF 1-I-EGF2 domain interfaces to obtain extension. The dashed line in C is drawn through the $\alpha \mathrm{l}$ and $\beta \mathrm{I}$ domain MIDAS metal ions. (D and E) Two representative electron microscopy negative stain class averages of $\alpha_{x} \beta_{2}$ ectodomain complexes with C3c, with schematics to right, from Chen et al. (2012). Bar, $10 \mathrm{~nm}$.

one crystal lattice and in the open conformation in another (Lee et al., 1995). In the latter lattice, the $\alpha_{M}$ MIDAS $\mathrm{Mg}^{2+}$ ion coordinated with a pseudo-ligand, a Glu residue in another $\alpha \mathrm{I}$ domain in the lattice. Although the previous isolated open $\alpha_{M} \alpha I$ domain and current open $\alpha_{\mathrm{x}} \alpha \mathrm{I}$ domain in an intact ectodomain are stabilized by lattice contacts, and these contacts are with different portions of the $\alpha \mathrm{I}$ domain, these lattice-stabilized open $\alpha \mathrm{I}$ domain conformations are essentially identical to one another and indistinguishable from those of open $\alpha_{2}$ and $\alpha_{\mathrm{L}} \alpha \mathrm{I}$ domains cocrystallized with biological ligands (Emsley et al., 2000; Shimaoka et al., 2003b). The similarities in open $\alpha$ I domain conformations stabilized by crystal lattices and biological ligands support the concept that crystal lattices select conformational states that are near local energy minima.

Although it is often convenient to think of conformational pathways as flowing in one direction, in general they are reversible. We may think of the crystal lattice as inducing the open $\alpha I$ domain state seen here. However, it is equally appropriate to think of the $\alpha_{X} \beta_{2}$ ectodomain as having multiple conformational states in solution. We may therefore think of the bent, internally liganded, cocked conformation as one of the biological conformations of $\alpha_{X} \beta_{2}$, which enabled crystallization in the particular lattice seen here.

The highly elongated $\alpha \mathrm{I}$ domain $\alpha 7$ helix seen here enables much greater flexibility of the $\alpha \mathrm{I}$ domain when bound to external ligand than had previously been imagined. Previous studies had shown that $\beta 6-\alpha 7$ loop conformation, but not $\alpha 7$ helix conformation, is canonical for the open conformation (Shimaoka et al., 2003b). Nonetheless, the amount of $\alpha 7$ helix extension seen here was surprising. It demonstrates that the interaction between the internal ligand and its binding pocket is quite strong and provides enough energy to break nine $\alpha$-helical hydrogen bonds in the $\alpha 7$ helix. Notably, there are no lattice contacts with the $\alpha 7$ helix itself (Fig. 3), showing that its highly elongated conformation is only a function of connecting to the $\alpha \mathrm{I}$ domain $\beta 6-\alpha 7$ loop at one end and the internal ligand at the other end. Indeed, the largely unwound $\alpha 7$ helix takes a more or less direct, overall straight path between these points. In the dehydrated crystal form, the orientation between the $\alpha \mathrm{I}$ domain and the body of the ectodomain differs, and the unwound $\alpha 7$ helix adjusts to again take a direct path between these points (Fig. $4 \mathrm{~F}$ and Fig. S2).

Flexibility between our two internally liganded $\alpha_{X} \beta_{2}$ structures is quantitated in Fig. 4 (I and J). Flexibility in the $\mathrm{N}$ linker largely occurs between Cys-126, which is disulfide bonded to the $\beta$ propeller domain, and Glu-130, which is integrated into the $\alpha \mathrm{I}$ domain with a backbone hydrogen bond (Fig. 4 I). Flexibility in the unwound $\alpha 7$ helix occurs between invariant Leu-303, which binds to the hydrophobic pocket below the $\beta 6-\alpha 7$ loop, and Lys-313, which is important in the internal ligand (Fig. $4 \mathrm{~J}$ ).

Although the specific orientations between the $\alpha$ I domain and body of the $\alpha_{X} \beta_{2}$ ectodomain seen here are trapped in crystals, there is reason to think that the orientation will be similar 
when $\alpha_{X} \beta_{2}$ engages physiological ligands on cell surfaces. Adhesion and binding to $\mathrm{iC} 3 \mathrm{~b}$ are strongly associated with extension and require the open headpiece conformation of $\alpha_{X} \beta_{2}$ (Chen et al., 2010, 2012). Our internally liganded, bent structures already reveal the open $\alpha$ I domain and how the internal ligand binds at the $\beta$ propeller- $\beta$ I interface. All that remains to make a model of extended-open $\alpha_{X} \beta_{2}$ using bent, internally liganded $\alpha_{X} \beta_{2}$ is to swing out the hybrid domain, using the open headpiece of $\alpha_{\mathrm{IIb}} \beta_{3}$ as the model, and to extend the $\alpha$ and $\beta$ subunits at their knees (Fig. 8). Integrins predominantly bind to the cytoskeleton through their $\beta$ subunit cytoplasmic domains (Gahmberg et al., 2009). Elongational force exerted by the cytoskeleton and resisted by an opsonized particle bound to the $\alpha_{X} \beta_{2} \alpha$ I domain will tend to straighten all the intervening domain-domain orientations. The resulting orientation between the $\alpha \mathrm{I}$ and $\beta \mathrm{I}$ domains, and the alignment of their axes, is very similar to that crystallized here (and distinct from that in bent-closed $\alpha_{X} \beta_{2}$ [Fig. 2 A]); a line drawn through the $\alpha \mathrm{I}$ and $\beta$ I MIDAS $\mathrm{Mg}^{2+}$ ions also passes through the $\beta I$-hybrid interface and continues in a similar direction as the hybrid domain would assume when swung out (Figs. 1 F, 2 B, and $8 \mathrm{C}$ ). Furthermore, the high affinity state of the $\alpha \mathrm{I}$ domain is more extended between the MIDAS and Glu-318 than the closed state, and the open headpiece is more extended between the $\beta I$ MIDAS and the end of the hybrid domain than the closed state (Astrof et al., 2006). Force times the difference in distance between conformational states gives a difference in energy. Therefore, cytoskeletal force applied across the integrin-ligand complex will stabilize the open, high affinity state over the closed, low affinity state, and help to offset the tendency of force to rupture adhesive bonds.

Despite these constraints that favor parallel, aligned $\alpha \mathrm{I}$ and $\beta I$ domain axes, there is likely to be considerable latitude for variation in $\alpha$ I MIDAS- $\beta$ I MIDAS distance and for rotation of the $\alpha$ I domain about the $\alpha$ I MIDAS- $\beta$ I MIDAS axis. The unwound $\alpha 7$ helix and $N$ linker each have highly extended conformations in the bent, internally liganded structures (Figs. $2 \mathrm{E}$, 3 , and $4[\mathrm{E}$ and $\mathrm{F}]$ ). A more compact conformation of the $\mathrm{N}$ linker, and less unwinding of the $\alpha 7$ helix, should enable shortening by $\sim 10 \AA$ of the $\alpha$ I MIDAS- $\beta$ I MIDAS distance. Lengthening also seems possible with untwisting (see next paragraph). Thus, substantially greater variation in $\alpha$ I MIDAS$\beta$ I MIDAS distance may occur than the increase from $63 \AA$ in the native crystal to $65 \AA$ in the dehydrated crystal seen here.

Looking down on the $\alpha$ I MIDAS, both connections of the $\alpha$ I domain to the ectodomain body are twisted $\sim 180^{\circ}$ in the counterclockwise direction in bent, internally liganded $\alpha_{X} \beta_{2}$ (Figs. 2 B and 3), whereas there is essentially no twisting in closed $\alpha_{X} \beta_{2}$ (Fig. 2 A). Because the $\mathrm{N}$ linker and unwound $\alpha 7$ helix are each highly extended, further counterclockwise twisting, as well as clockwise untwisting, of internally liganded $\alpha_{X} \beta_{2}$ is easily attainable without creating clashes between the $\alpha$ I domain and the remainder of the integrin headpiece.

Complexes of integrin $\alpha_{X} \beta_{2}$ ectodomain with the C3c moiety of its ligand iC 3 b (Chen et al., 2012) are suggestive of such $\alpha$ I domain rotation (Fig. 8, D and E). Negative stain electron microscopy shows two classes of $\mathrm{C} 3 \mathrm{c} \alpha_{\mathrm{X}} \beta_{2}$ complexes with indistinguishable orientations of $\alpha_{X} \beta_{2}$ but orientations of C3c that are flipped $180^{\circ}$ (Fig. 8, D and E). The orientation of the integrin $\alpha \mathrm{I}$ domain is not discernable. However, the orientation of the remainder of $\alpha_{X} \beta_{2}$ and three bound Fab fragments is quite clear (Fig. 8, D and E, schematics). Similarly, the orientation of $\mathrm{C} 3 \mathrm{c}$, with its distinctive head-like $\mathrm{C} 345 \mathrm{C} \mathrm{knob}$, is quite clear. The lack of significant interaction between the body of the open $\alpha \mathrm{I}$ domain and the headpiece in the internal ligand-bound $\alpha_{X} \beta_{2}$ crystal structures now allow us to interpret these images. It is unlikely that such a large rotation could occur at the ligand-receptor interface between $\mathrm{C} 3 \mathrm{c}$ and the $\alpha \mathrm{I}$ domain. In contrast, our structures suggest that rotation can readily occur between the $\alpha \mathrm{I}$ domain and the headpiece, and the images in Fig. 8 (D and E) suggest that a rotation of at least $180^{\circ}$ is readily obtainable in $\alpha_{X} \beta_{2}$.

The ability of the $\alpha \mathrm{I}$ domain to bind ligand at a range of distances and rotations relative to the reminder of the integrin endows $\alpha$ I integrins with great versatility. Although $\alpha$ I-less integrins are present in all metazoans, from sponges to vertebrates, $\alpha \mathrm{I}$ integrins are known only in chordates (Whittaker and Hynes, 2002). $\alpha$ I $\alpha$ subunits expanded in vertebrates to comprise half of all integrin $\alpha$ subunits. The flexibility of $\alpha \mathrm{I}$ domains, both in the closed state as shown previously (Xie et al., 2010) and in the open state shown here, may give $\alpha \mathrm{I}$ integrins an advantage over $\alpha$ I-less integrins for recognition of certain types of ligands. These may include ligands in less accessible environments, including collagens in bundles (integrins $\alpha_{1} \beta_{1}, \alpha_{2} \beta_{1}, \alpha_{10} \beta_{1}$, and $\alpha_{11} \beta_{1}$ ), adhesion molecules on cell surfaces (integrins $\alpha_{L} \beta_{2}$ and $\alpha_{E} \beta_{7}$ ), and foci of complement activation on pathogen surfaces (integrins $\alpha_{M} \beta_{2}$ and $\alpha_{X} \beta_{2}$ ).

In cocking, the $\beta$ I domain $\alpha 1^{\prime}$ helix moves more than in any previously described intermediate state of $\beta_{1}$ or $\beta_{3}$ integrins (Fig. 6 and Table 2; Xiong et al., 2002; Nagae et al., 2012; Zhu et al., 2013). We therefore examined $\beta_{2}$ for specializations that could support the cocked conformation. The $\alpha 1$ and $\alpha 1^{\prime}$ helices lie in a groove formed by the $\alpha 7$ helix on one side and the $\alpha 2$ helix on the other (Fig. 9 A). Any features that facilitate helix sliding in this groove toward the MIDAS would promote formation of the cocked state. One such feature is a wider groove in $\beta_{2}$ that is lined with smaller side chains (Fig. 9 A).

In the most striking specialization of $\beta_{2}$ for cocking, residue Leu-127 in the $\beta$ I domain $\alpha 1^{\prime}$ helix is precocked in the closed conformation. Residues corresponding to $\beta_{2}$ Val-124, Leu-127, Leu-131, Leu-135, and Ile-138 are conserved as hydrophobic in all eight vertebrate integrin $\beta$ subunits (Fig. 9). The corresponding residues in $\beta_{1}$ and $\beta_{3}$ are completely buried in the $\alpha 1 / \alpha 1^{\prime}$ groove (Fig. 9, B and D). However, ratchet residue Leu-127 in $\beta_{2}$ is exceptional; as described in Results, it is not buried (Fig. 9 C). Additionally, although $\alpha 1^{\prime}$ helix residue Leu-131 is buried in $\beta_{2}$ as in other integrin $\beta$ subunits, it adopts a different rotamer that places its center $3 \AA$ closer to the $\beta 1-\alpha 1$ loop (Fig. 9). The Leu-135 residue in $\beta_{2}$ also is more aligned with and forward in the groove than the equivalent Met residue in $\beta_{1}$ and $\beta_{3}$.

The residue equivalent to $\beta_{2}$ Val-330 in the $\beta 6-\alpha 7$ loop points toward the $\alpha 1^{\prime}$ helix and may be considered a gatekeeper for $\beta$ I domain shape shifting (Fig. 9 A). The partially exposed, relatively high position of Leu-127 in the groove in the precocked state of $\beta_{2}$ enables it during cocking to pass Val330 by vaulting over the gate. 

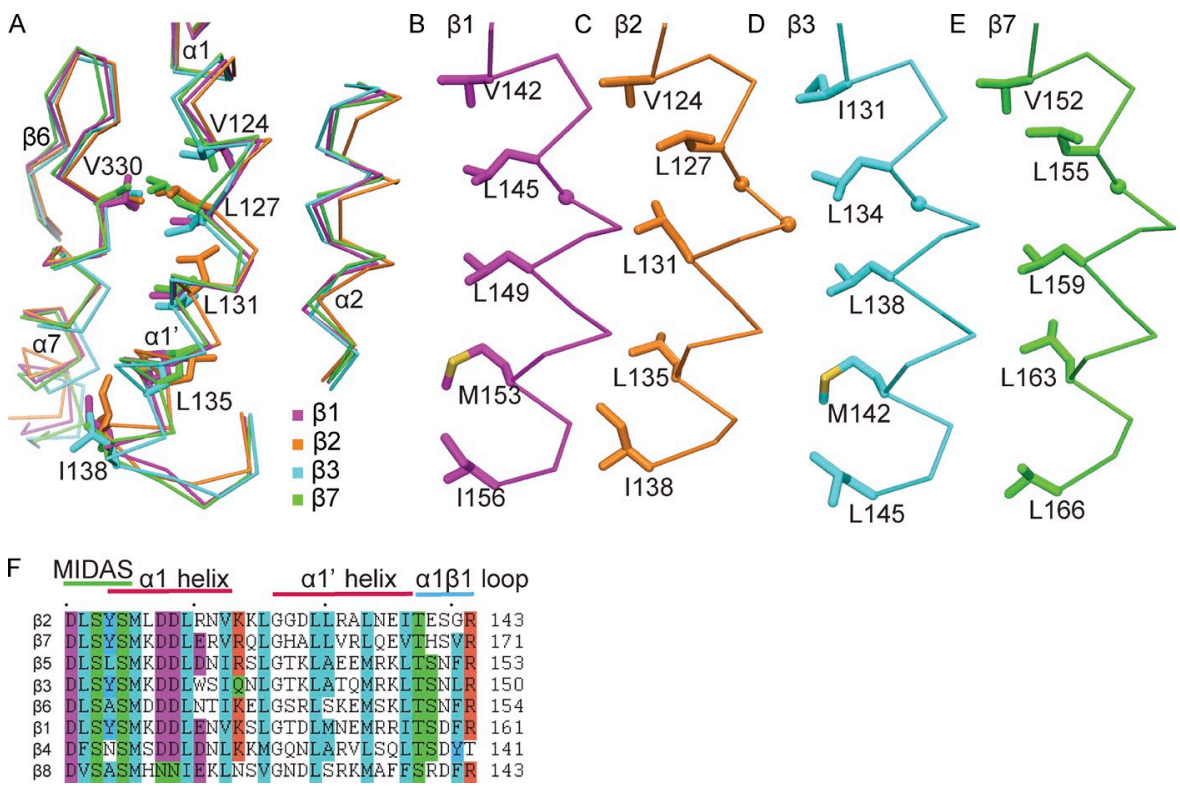

The order of secondary structure movements thus differs in intermediate states of $\beta_{2}$ and $\beta_{3}$ integrins. In $\beta_{2}$, large movements of the $\alpha 1$ and $\alpha 1^{\prime}$ helices occur with no movement of gatekeeper residue Val-330 in the cocked conformation. In $\beta_{3}$, movement of the gatekeeper Val-340 residue precedes $\alpha 1^{\prime}$ helix sliding (Zhu et al., 2013).

Do other integrin $\beta$ subunits have a precocked configuration of $\beta$ I domain $\alpha 1$ and $\alpha 1^{\prime}$ helix hydrophobic residues, suggesting they might also undergo cocking? The $\beta_{1}$ and $\beta_{7}$ subunits are particularly interesting because they can associate with both $\alpha \mathrm{I}$ and $\alpha \mathrm{I}$-less integrin $\alpha$ subunits ( $\beta_{2}$ is unique in only associating with $\alpha \mathrm{I} \alpha$ subunits). In $\beta 1$, the first four hydrophobic $\alpha 1$ and $\alpha 1^{\prime}$ helix residues are chemically identical to those in $\beta_{3}$, and their side chains are in essentially identical positions. In contrast, in $\beta_{7}$, Leu-155 has a solvent-exposed rotamer identical to that of key $\beta_{2}$ ratchet residue Leu-127 (Fig. 9 E). $\beta_{7}$ like $\beta_{2}$ also has Leu in the fourth hydrophobic position, whereas $\beta_{1}, \beta_{3}$, and $\beta_{6}$ all have a Met residue at this position (Fig. 9 F). These comparisons suggest that a cocked conformation might also be found for the leukocyte integrins $\alpha_{4} \beta_{7}$ and $\alpha_{\mathrm{E}} \beta_{7}$.

Cocking thus has been found for $\beta_{2}$ integrins and is predicted for $\beta_{7}$ integrins, which are unique among integrins in only being expressed on leukocytes. $\beta_{2}$ has higher sequence identity to $\beta_{7}$ than to any other integrin $\beta$ subunit: $46 \%$ in the ectodomain and $67 \%$ in the $\beta I$ domain, whereas the values range from 31 to $42 \%$ and 43 to $54 \%$, respectively, for the other six integrin $\beta$ subunits (Fig. S5). This level of sequence identity is consistent with similar regulatory specializations in $\beta_{2}$ and $\beta_{7}$ integrins.

Previously, the process of $\alpha \mathrm{I}$ integrin activation has been presumed to require transitions between five states, a bent conformation with separated lower legs (Fig. 1 B), an extended conformation with a closed $\beta$ I domain (Fig. 1 C), an extended conformation with an open $\beta$ I domain (Fig. 1 D), and an extended conformation with open $\beta I$ and $\alpha I$ domains (Fig. 1 F). With the requirement for four transition states, each with an energy barrier that must be traversed before the next state is
Figure 9. Precocked configurations of residues in $\alpha 1$ and $\alpha l^{\prime}$ helices of the closed conformations of $\beta_{2}$ and $\beta_{7}$ and not $\beta_{1}$ and $\beta_{3}$ integrin $\boldsymbol{\beta}$ subunits. (A) The $\alpha 1$ and $\alpha l^{\prime}$ helices with neighboring $\alpha 7$ and $\alpha 2$ helices of superimposed closed $\beta$ I domains. $\beta_{2}$ subunit hydrophobic residues are labeled. (B-E) A different view of the $\alpha 1$ and $\alpha 1^{\prime}$ helices from the superimposed $\beta$ I domains, after horizontal separation on the page. The color scheme in $A$ is the same as in B-E. $C \alpha$ atom traces are shown with key hydrophobic residues in stick and Gly as $C_{\alpha}$ sphere. (F) $\alpha 1$ and $\alpha l^{\prime}$ helix region sequences of all human integrin $\beta$ subunits. Dots mark decadal residues in $\beta_{2}$. Structures are $\beta_{1}$ (PDB ID no. 3VI3), $\beta_{3}$ (PDB ID no. 3T3P), and $\beta_{7}$ (PDB ID no. 3V4P). reached, activation could be slow. The metastable internal ligand-bound and cocked states defined here have several important implications for speeding conformational transitions in $\beta_{2}$ integrins and possibly in $\beta_{7}$ integrins. They directly connect the bent conformation to the extended conformation with open $\beta I$ and $\alpha \mathrm{I}$ domains (Fig. $1 \mathrm{E}$ ). Hybrid domain swing-out is unimpeded in the bent conformation (Takagi et al., 2002) and would bring with it the lower $\beta$ leg, thus inducing lower leg separation and extension as well as headpiece opening in one fell swoop (Fig. 1, E and F). Therefore, all key conformational transitions could be accomplished with a single intermediate, internal ligandbound state. The internal ligand-bound state of the $\beta I$ domain found here lowers the energy barrier of the transition state for conformational change by enabling the $\beta \mathrm{I}$ domain to activate the $\alpha \mathrm{I}$ domain before $\beta$ I opening and integrin extension. $\alpha$ I domain opening may thus occur before $\beta \mathrm{I}$ domain opening (Fig. $1 \mathrm{E}$ ), instead of in the reverse order (Fig. 1 D). The cocked conformation of the $\beta I$ domain must lower the energy of the internal ligand-bound state even further because it is found in the absence of countervailing lattice interactions. In terms of $\alpha 1$ and $\alpha 1^{\prime}$ helix movement, the cocked conformation is more than halfway to the open conformation (Table 2). The internal ligand-bound, cocked, bent conformation is thus clearly on the pathway to the extended conformation with open $\alpha \mathrm{I}$ and $\beta I$ domains (Fig. 1, E and F).

The importance of the bent, internal ligand-bound metastable state in integrin extension and headpiece opening postulated here is supported by previous work on LFA-1 (integrin $\alpha_{\mathrm{L}} \beta_{2}$; Salas et al., 2004). This work showed that $\alpha_{\mathrm{L}}$ Glu-310 (equivalent to $\alpha_{X}$ Glu-318) is important for inducing LFA-1 extension, consistent with passage of $\beta_{2}$ integrins through an intermediate similar to that shown in Fig. $1 \mathrm{E}$ on the pathway to extension. Furthermore, the experimental requirement of $\alpha_{\mathrm{L}}$ Glu-310 for leukocyte rolling and $\mathrm{Mn}^{2+}$-induced $\beta_{2}$ integrin extension (Salas et al., 2004) is inconsistent with the pathway for extension shown in Fig. 1 (A-C). Like $\alpha_{L} \beta_{2}, \alpha_{X} \beta_{2}$ extension on cell surfaces is facilitated by the internal ligand, as shown here with inhibition by four different Glu-318 mutations of $\mathrm{Mn}^{2+}$-dependent KIM127 
expression. Thus, equilibration between bent and extended $\beta_{2}$ integrin conformational states on cell surfaces may require brief flickering to metastable conformational states similar to the internally liganded and cocked conformations seen here.

In intact integrins on cell surfaces, the $\alpha$ I domain is likely to spontaneously equilibrate between closed and open states. After $\alpha$ I domain opening, the internal ligand would be exposed to solvent, but probably not yet in its bound conformation. As part of the same molecule, the internal ligand would have a very high local concentration near the internal ligand-binding pocket. Binding to the internal ligand-binding pocked should therefore occur rapidly and yield a structure similar to our internally liganded, uncocked structure. This metastable state would then transition to a lower energy, but still metastable, internally liganded, cocked structure. Opening of the $\beta$ I domain could then follow with hybrid domain swing-out, destabilizing interfaces between the headpiece and lower legs and between the lower $\alpha$ and $\beta$ legs, and result in integrin extension. Our two metastable crystal structures thus provide a structural pathway that explains the experimentally demonstrated importance of the Glu of the internal ligand in integrin extension on cell surfaces.

Kinetic rates are determined by the height of the energy barrier that needs to be traversed at the transition state. The metastable transition state defined here implicitly defines a mechanism for lowering the energy barrier for integrin conformational change and thus for increasing kinetics. Measuring these kinetics is an important topic for further research.

A remarkable finding in this study is the extensive interface buried upon binding of the internal ligand, and the extensive reshaping of the $\alpha \mathrm{I}$ domain $\alpha 7$ helix and $\mathrm{C}$ linker to form the internal ligand. This interface's size, excellent hydrogen bonding, and burial of the Glu-318 MIDAS interaction by hydrophobic internal ligand residues must contribute to its strength and its ability to pay the energetic cost of extensively unwinding the $\alpha$ I domain $\alpha 7$ helix. The results certainly support previous suggestions that the invariant Glu following $\alpha \mathrm{I}$ domains has a function similar to the Asp of Arg-Gly-Asp (Alonso et al., 2002), of "exertion of a bell-rope-like pull on a segment within the C-terminal linker region" and "interaction of the C-terminal linker with the $\beta$ propeller and/or the $\beta$ I domain" at a site "equivalent to the ligand-binding site in integrins that lack $\alpha \mathrm{I}$ domains," and that "the $\alpha \mathrm{I}, \beta$ propeller, and $\beta \mathrm{I}$ domains make a ternary interaction interface" (Shimaoka et al., 2002).

Yet the internally liganded and cocked states yield further unexpected discoveries. The surprising lift-off of the $\alpha \mathrm{I}$ domain over the $\beta$ propeller and $\beta$ I domain platform enables a range of extensional and rotational motions that are without precedent in other allosteric machines. The metastable, internally liganded, cocked structure enables rapid equilibration between bent and extended-open integrin structures and an explicit mechanism for linking integrin extension and headpiece opening. Finally, the difference in order of secondary structure movements in opening of $\beta_{2}$ and $\beta_{3} \beta$ I domains and the cocked conformation special to $\beta_{2}$ demonstrate that integrin $\beta$ subunits can be specialized not only to modulate ligand recognition but also to assume different intermediate states between closed and open, with important consequences for signal transmission in integrin ectodomains.

\section{Materials and methods}

Protein expression, purification, and crystallization

In previous $\alpha_{x} \beta_{2}$ crystal structures (Xie et al., 2010) the most C-terminal residues visible in density, $\alpha_{\times} \mathrm{K} 1082$ and $\beta_{2}$ V674, are 15 to $18 \AA$ apart, whereas $\alpha_{X}$ N920 and $\beta_{2}$ V674 are 7 to $10 \AA$ apart ( $\alpha \alpha$ distances). The $\alpha_{x} \mathrm{~N} 920 \mathrm{C}$ and $\beta_{2}$ V674C mutations formed a disulfide and expressed well. $\alpha_{X}$ subunit cDNA encoding mature residues $1-1082$ was fused to a $C$-terminal 53-residue sequence (5'-PAALQTLFQGPLGAQLEKELQALEKENAQLEWELQALEKELAQHHHHHHA-3') and inserted in ET 1 vector containing an internal initiation site for enhanced GFP (Mi et al., 2008). $\beta_{2}$ cDNA encoding the signal sequence and mature residues $1-674 \mathrm{C}$ was fused to $\mathrm{C}$-terminal sequence 5'-GPAALQTLFQGPLGAQLKKKLQALKKKNAQLKWKLQALKKKLAQTTGWRGGHVVEGLAGELEQLRARLEHHPQGQREPHHHHHHA-3' and inserted in $\mathrm{pEF} 1$ puro vector (Takagi et al., 2001). The two C-terminal sequences contained a $3 \mathrm{C}$ protease recognition site (bold), ACID or BASE coiled-coils (underlined; O'Shea et al., 1993), respectively, a streptavidin binding peptide sequence (in $\beta_{2}$ construct only; italics), and a hexahistidine tag.

$N$-linked sites in $\alpha_{x}$ (nine) and in $\beta_{2}$ (six) were individually tested for effect on transient expression of soluble heterodimer using a capture ELISA. All mutations were done with QuikChange XL (Agilent Technologies). Individual elimination of five $\alpha_{x}$ sites and four $\beta_{2}$ sites had no adverse effect. After testing combinations of multiple substitutions, we used five substitutions in $\alpha_{x}$ (N42D, N368S, N678T, N885S, and N920C) and two in $\beta_{2}$ (N190D and N232K), resulting in expression at $30 \%$ of wild-type levels. HEK293S N-acetylglucosaminyl transferase I-negative $\left(\mathrm{GnTl}^{-1-}\right)$ cells, which express high mannose but not complex $\mathrm{N}$-glycans (Reeves et al., 2002), were transfected using calcium phosphate, isolated by sorting for single GFP+ cells, and selected with $10 \mu \mathrm{g} / \mathrm{ml}$ puromycin and $1 \mathrm{mg} / \mathrm{ml} \mathrm{G} 418$. A clone with high expression was cultured in Ex-Cell 293 medium (Sigma-Aldrich) in square bottles (Muller et al., 2005). Culture supernatant supplemented with $20 \mathrm{mM}$ Tris, pH 8.2, $200 \mathrm{mM} \mathrm{NaCl}$, and $0.25 \mathrm{mM} \mathrm{NiCl}{ }_{2}$ was centrifuged at $3,000 \mathrm{~g}$, concentrated fivefold using tangential flow with a 100,000 Mr cutoff, diluted twofold, concentrated twofold, and loaded on Ni-NTA (10 ml/l supernatant) equilibrated in $20 \mathrm{mM}$ Tris, $\mathrm{pH} 8,150 \mathrm{mM} \mathrm{NaCl}, 1 \mathrm{mM} \mathrm{CaCl}, 5 \mathrm{mM} \mathrm{MgCl}$, and $13 \mathrm{mM}$ imidazole (loading buffer). After washing with 10 column volumes of loading buffer, a Strep-tactin Sepharose (IBA GmbH; $2.5 \mathrm{ml} / \mathrm{l}$ supernatant) column was attached downstream and the NTA column was eluted with 10 column volume of loading buffer plus $250 \mathrm{mM}$ imidazole. The Strep-tactin column was washed with 10 column volumes of $20 \mathrm{mM}$ Hepes, $\mathrm{pH} 7,150 \mathrm{mM} \mathrm{NaCl}, 1 \mathrm{mM} \mathrm{CaCl}$, and $5 \mathrm{mM} \mathrm{MgCl}_{2}$ and eluted in the same buffer containing $2.5 \mathrm{mM}$ desthiobiotin. After tag and coiled-coil removal with $3 \mathrm{C}$ protease, a final step of size exclusion chromatography using a Superdex S200 column demonstrated that the material was largely monomeric (Fig. S1 A). The $\alpha_{X}$ and $\beta_{2}$ bands are unusually sharp in SDSPAGE because of the small number of $\mathrm{N}$-linked sites, and native PAGE showed a single band (Fig. S1, A and B). Final yield was $\sim 3.5 \mathrm{mg} / \mathrm{l}$ of culture supernatant.

Protein was concentrated to $9 \mathrm{mg} / \mathrm{ml}$ and screened for crystallization using sitting and hanging drop vapor diffusion at $4^{\circ} \mathrm{C}$. Microseeding improved crystal quality. Rod-like crystals formed (Fig. S1 C) in an optimized solution of $6 \%$ PEG 8000, $0.2 \mathrm{M}$ magnesium acetate, and

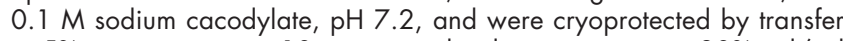
in $5 \%$ increments over 10 min to mother liquor containing 30\% vol/vol glycerol. One crystal was dehydrated (and cryoprotected) by transfer into $15 \%$ PEG 20000, $0.1 \mathrm{M}$ sodium cacodylate, $\mathrm{pH} 7.2$, and $0.2 \mathrm{M}$ magnesium acetate and overnight vapor diffusion equilibration. Crystals were frozen in liquid nitrogen.

Diffraction data collected at APS beamline ID-23 was processed with XDS (Kabsch, 2001). The structure was solved by molecular replacement using the $\alpha_{X} \alpha \mid$ domain (PDB ID no. 1N3Y) and $\beta$ propeller and $\beta 1$ domains (PDB ID no. 3K6S) using PHASER (McCoy et al., 2007). Other domains from 3K6S were placed into the map manually, and an initial model was obtained by refining each domain as a rigid body. After torsion angle-simulated annealing, many rounds were performed of rebuilding with Coot (Emsley and Cowtan, 2004) and refinement with PHENIX (Adams et al., 2010). The model was further validated and improved, and Ramachandran statistics were calculated using MOLPROBITY (Davis et al., 2007). Simulated annealing composite omit $2 \mathrm{Fo}$-Fc electron density was calculated with PHENIX with 128 omitted regions (Adams et al., 2010).

\section{Superpositions and figures}

All superpositions were on $\mathrm{C} \alpha$ atoms of indicated domains. Superimposed structures are shown in identical orientations and are aligned vertically 
or horizontally on the page. Figures were prepared with PyMol. Detailed comparisons of the closed $\beta_{2} \beta$ l domain use a structure of the $\alpha_{L} \beta_{2}$ headpiece, which has metal ions at all three sites in the $\beta I$ domain, has better density for the $\beta$ I domain, and is at higher resolution $(2.5 \AA)$ than the $\alpha \times \beta_{2}$ ectodomain (Xie et al., 2010).

\section{Mutations}

Rosetta-fixed backbone design (Kuhlman et al., 2003) was used to predict mutations that differentially destabilized the previous (Xie et al., 2010; PDB ID no. 3K6S) and current $\alpha_{x} \beta_{2}$ structures. For each residue from $\alpha_{x} 296$ to 326 , the Rosetta energy function (score 12) was calculated for each of the 20 amino acids. Mutations were chosen that showed differential effects, destabilized one structure little, and after inspection by molecular graphics appeared unlikely to be changed in effect by minor backbone movements.

\section{Rosetting and epitope exposure}

Sheep erythrocytes were sensitized with iC3b as follows. To prepare E-lgM$\mathrm{iC} 3 \mathrm{~b}$, erythrocytes were incubated with IgM anti-Forssman $\mathrm{mAb} M 1 / 87$, washed three times, and treated at $37^{\circ} \mathrm{C}$ for $1 \mathrm{~h}$ with human $\mathrm{C} 5$-deficient serum as described previously (Bilsland et al., 1994). E-lgM were prepared by the same method but omitting the final sensitization with $\mathrm{C} 5$-deficient serum. E-lgM-iC $3 b$ and E-lgM as control were assayed for binding to $\alpha_{x} \beta_{2}$ HEK293T transfectants (105 cells/well in cluster-24 plates; Zang and Springer, 2001). In brief, $250 \mu \mathrm{l}$ of E-lgM-iC3b in HBS was added and incubated for $1.5 \mathrm{~h}$ at $37^{\circ} \mathrm{C}$. After three washes, rosettes (>10 erythrocytes/HEK293T cell, over 100 HEK293T cells examined) were scored by microscopy.

Immunofluorescent flow cytometry (Lu et al., 2001) used fluorescein (FITC)-labeled CBR LFA1/7 and biotinylated KIM127, MEM148, or m24, referenced elsewhere (Chen et al., 2010), in the presence of $1 \mathrm{mM} \mathrm{MgCl}$ / $\mathrm{CaCl}_{2}$ or $1 \mathrm{mM} \mathrm{MnCl}$. HEK293T transfectants were stained with phycoerythrin-streptavidin to recognize the activation-dependent epitopes. A single FITC gate was set for all samples that included few nontransfected cells and used to collect PE fluorescence. Mutant phycoerythrin mean fluorescence intensity (MFI) was normalized by multiplying it by (FITC MFI of wild-type)/(FITC MFI of mutant). Results for both rosetting and immunofluorescence are averages \pm SD of replicates from at least three independent transfections with three different replicates (transfectants seeded in three different wells) each.

\section{Online supplemental material}

Fig. S1 shows purification, PAGE, and crystals of $\alpha_{x} \beta_{2}$. Fig. S2 shows differences in interdomain angles among different $\alpha_{x} \beta_{2}$ structures. Fig. S3 shows simulated annealing composite omit map density for the internal ligand and the $\beta \mid$ domain $\alpha 1 / \alpha l^{\prime}$ helices. Fig. S4 compares the internal ligand and $C$ linker in native and dehydrated structures. Fig. S5 shows sequence relationships among integrin $\beta$ subunits. Online supplemental material is available at http://www.jcb.org/cgi/content/full/jcb.201308083/DC1.

We thank Jianghai Zhu for help with data processing and the staff of Advanced Photon Source beamline 23-ID (GM/CA-CAT).

This work was supported by National Institutes of Health grant NIAID Al072756 and a GlaxoSmithKline fellowship.

Submitted: 14 August 2013

Accepted: 18 October 2013

\section{References}

Adams, P.D., P.V. Afonine, G. Bunkóczi, V.B. Chen, I.W. Davis, N. Echols, J.J. Headd, L.W. Hung, G.J. Kapral, R.W. Grosse-Kunstleve, et al. 2010. PHENIX: a comprehensive Python-based system for macromolecular structure solution. Acta Crystallogr. D Biol. Crystallogr. 66:213-221. http://dx.doi.org/10.1107/S0907444909052925

Alonso, J.L., M. Essafi, J.P. Xiong, T. Stehle, and M.A. Arnaout. 2002. Does the integrin alphaA domain act as a ligand for its betaA domain? Curr. Biol. 12:R340-R342. http://dx.doi.org/10.1016/S0960-9822(02)00852-7

Astrof, N.S., A. Salas, M. Shimaoka, J.F. Chen, and T.A. Springer. 2006. Importance of force linkage in mechanochemistry of adhesion receptors. Biochemistry. 45:15020-15028. http://dx.doi.org/10.1021/bi061566o

Bilsland, C.A.G., M.S. Diamond, and T.A. Springer. 1994. The leukocyte integrin $\mathrm{p} 150,95(\mathrm{CD} 11 \mathrm{c} / \mathrm{CD} 18)$ as a receptor for $\mathrm{iC} 3 \mathrm{~b}$. Activation by a heterologous $\beta$ subunit and localization of a ligand recognition site to the I domain. J. Immunol. 152:4582-4589.

Chen, X., C. Xie, N. Nishida, Z. Li, T. Walz, and T.A. Springer. 2010. Requirement of open headpiece conformation for activation of leukocyte integrin
alphaXbeta2. Proc. Natl. Acad. Sci. USA. 107:14727-14732. http://dx.doi .org/10.1073/pnas.1008663107

Chen, X., Y. Yu, L.-Z. Mi, T. Walz, and T.A. Springer. 2012. Molecular basis for complement recognition by integrin $\alpha \mathrm{X} \beta 2$. Proc. Natl. Acad. Sci. USA. 109:4586-4591. http://dx.doi.org/10.1073/pnas.1202051109

Davis, I.W., A. Leaver-Fay, V.B. Chen, J.N. Block, G.J. Kapral, X. Wang, L.W. Murray, W.B. Arendall III, J. Snoeyink, J.S. Richardson, and D.C. Richardson. 2007. MolProbity: all-atom contacts and structure validation for proteins and nucleic acids. Nucleic Acids Res. 35(Web Server issue):W375-W383. http://dx.doi.org/10.1093/nar/gkm216

Emsley, P., and K. Cowtan. 2004. Coot: model-building tools for molecular graphics. Acta Crystallogr. D Biol. Crystallogr. 60:2126-2132. http:// dx.doi.org/10.1107/S0907444904019158

Emsley, J., C.G. Knight, R.W. Farndale, M.J. Barnes, and R.C. Liddington. 2000. Structural basis of collagen recognition by integrin $\alpha 2 \beta 1$. Cell. 101:47-56. http://dx.doi.org/10.1016/S0092-8674(00)80622-4

Gahmberg, C.G., S.C. Fagerholm, S.M. Nurmi, T. Chavakis, S. Marchesan, and M. Grönholm. 2009. Regulation of integrin activity and signalling. Biochim. Biophys. Acta. 1790:431-444. http://dx.doi.org/10.1016/j.bbagen.2009.03 .007

Huth, J.R., E.T. Olejniczak, R. Mendoza, H. Liang, E.A. Harris, M.L. Lupher Jr., A.E. Wilson, S.W. Fesik, and D.E. Staunton. 2000. NMR and mutagenesis evidence for an I domain allosteric site that regulates lymphocyte function-associated antigen 1 ligand binding. Proc. Natl. Acad. Sci. USA. 97:5231-5236. http://dx.doi.org/10.1073/pnas.97.10.5231

Kabsch, W.2001. Chapter 25.2.9XDS.In International Tables for Crystallography, Volume F: Crystallography of Biological Macromolecules. M.G. Rossmann and E.V. Arnold, editors. Kluwer Academic Publishers, Dordrecht. 730-734.

Karplus, P.A., and K. Diederichs. 2012. Linking crystallographic model and data quality. Science. 336:1030-1033. http://dx.doi.org/10.1126/science .1218231

Kuhlman, B., G. Dantas, G.C. Ireton, G. Varani, B.L. Stoddard, and D. Baker. 2003. Design of a novel globular protein fold with atomic-level accuracy. Science. 302:1364-1368. http://dx.doi.org/10.1126/science.1089427

Lee, J.-O., L.A. Bankston, M.A. Arnaout, and R.C. Liddington. 1995. Two conformations of the integrin A-domain (I-domain): a pathway for activation? Structure. 3:1333-1340. http://dx.doi.org/10.1016/S0969-2126 (01)00271-4

Lu, C., M. Ferzly, J. Takagi, and T.A. Springer. 2001. Epitope mapping of antibodies to the $C$-terminal region of the integrin $\beta_{2}$ subunit reveals regions that become exposed upon receptor activation. J. Immunol. 166:5629-5637.

Luo, B.-H., C.V. Carman, and T.A. Springer. 2007. Structural basis of integrin regulation and signaling. Annu. Rev. Immunol. 25:619-647. http://dx.doi .org/10.1146/annurev.immunol.25.022106.141618

McCoy, A.J., R.W. Grosse-Kunstleve, P.D. Adams, M.D. Winn, L.C. Storoni, and R.J. Read. 2007. Phaser crystallographic software. J. Appl. Cryst. 40:658-674. http://dx.doi.org/10.1107/S0021889807021206

Mi, L.Z., M.J. Grey, N. Nishida, T. Walz, C. Lu, and T.A. Springer. 2008. Functional and structural stability of the epidermal growth factor receptor in detergent micelles and phospholipid nanodiscs. Biochemistry. 47:10314-10323. http://dx.doi.org/10.1021/bi801006s

Muller, N., P. Girard, D.L. Hacker, M. Jordan, and F.M. Wurm. 2005. Orbital shaker technology for the cultivation of mammalian cells in suspension. Biotechnol. Bioeng. 89:400-406. http://dx.doi.org/10.1002/bit.20358

Nagae, M., S. Re, E. Mihara, T. Nogi, Y. Sugita, and J. Takagi. 2012. Crystal structure of $\alpha 5 \beta 1$ integrin ectodomain: atomic details of the fibronectin receptor. J. Cell Biol. 197:131-140. http://dx.doi.org/10 1083/jcb.201111077

Nishida, N., C. Xie, M. Shimaoka, Y. Cheng, T. Walz, and T.A. Springer. 2006. Activation of leukocyte $\beta_{2}$ integrins by conversion from bent to extended conformations. Immunity. 25:583-594. http://dx.doi.org/10.1016/ j.immuni.2006.07.016

O'Shea, E.K., K.J. Lumb, and P.S. Kim. 1993. Peptide 'Velcro': design of a heterodimeric coiled coil. Curr. Biol. 3:658-667. http://dx.doi .org/10.1016/0960-9822(93)90063-T

Reeves, P.J., N. Callewaert, R. Contreras, and H.G. Khorana. 2002. Structure and function in rhodopsin: high-level expression of rhodopsin with restricted and homogeneous N-glycosylation by a tetracycline-inducible $\mathrm{N}$-acetylglucosaminyltransferase I-negative HEK293S stable mammalian cell line. Proc. Natl. Acad. Sci. USA. 99:13419-13424. http://dx.doi .org/10.1073/pnas.212519299

Salas, A., M. Shimaoka, A.N. Kogan, C. Harwood, U.H. von Andrian, and T.A. Springer. 2004. Rolling adhesion through an extended conformation of integrin alphaLbeta 2 and relation to $\alpha$ I and $\beta$ I-like domain interaction. Immunity. 20:393-406. http://dx.doi.org/10.1016/ S1074-7613(04)00082-2 
Schürpf, T., and T.A. Springer. 2011. Regulation of integrin affinity on cell surfaces. EMBO J. 30:4712-4727. http://dx.doi.org/10.1038/emboj.2011.333

Shamri, R., V. Grabovsky, J.M. Gauguet, S. Feigelson, E. Manevich, W. Kolanus, M.K. Robinson, D.E. Staunton, U.H. von Andrian, and R. Alon. 2005. Lymphocyte arrest requires instantaneous induction of an extended LFA-1 conformation mediated by endothelium-bound chemokines. Nat. Immunol. 6:497-506. http://dx.doi.org/10.1038/ni1194

Shimaoka, M., J. Takagi, and T.A. Springer. 2002. Conformational regulation of integrin structure and function. Annu. Rev. Biophys. Biomol. Struct. 31:485516. http://dx.doi.org/10.1146/annurev.biophys.31.101101.140922

Shimaoka, M., A. Salas, W. Yang, G. Weitz-Schmidt, and T.A. Springer. 2003a. Small molecule integrin antagonists that bind to the $\beta 2$ subunit I-like domain and activate signals in one direction and block them in the other. Immunity. 19:391-402. http://dx.doi.org/10.1016/S10747613(03)00238-3

Shimaoka, M., T. Xiao, J.-H. Liu, Y. Yang, Y. Dong, C.-D. Jun, A. McCormack, R. Zhang, A. Joachimiak, J. Takagi, et al. 2003b. Structures of the $\alpha$ L I domain and its complex with ICAM-1 reveal a shape-shifting pathway for integrin regulation. Cell. 112:99-111. http://dx.doi.org/10.1016/ S0092-8674(02)01257-6

Springer, T.A., and M.L. Dustin. 2012. Integrin inside-out signaling and the immunological synapse. Curr. Opin. Cell Biol. 24:107-115. http:// dx.doi.org/10.1016/j.ceb.2011.10.004

Springer, T.A., J. Zhu, and T. Xiao. 2008. Structural basis for distinctive recognition of fibrinogen $\gamma \mathrm{C}$ peptide by the platelet integrin $\alpha_{\text {апь }} \beta_{3} . J$. Cell Biol. 182:791-800. http://dx.doi.org/10.1083/jcb.200801146

Takagi, J., H.P. Erickson, and T.A. Springer. 2001. C-terminal opening mimics 'inside-out' activation of integrin $\alpha_{5} \beta_{1}$. Nat. Struct. Biol. 8:412-416. http://dx.doi.org/10.1038/87569

Takagi, J., B.M. Petre, T. Walz, and T.A. Springer. 2002. Global conformational rearrangements in integrin extracellular domains in outside-in and inside-out signaling. Cell. 110:599-11. http://dx.doi.org/10.1016/ S0092-8674(02)00935-2

Weitz-Schmidt, G., T. Schürpf, and T.A. Springer. 2011. The C-terminal $\alpha \mathrm{I}$ domain linker as a critical structural element in the conformational activation of $\alpha \mathrm{I}$ integrins. J. Biol. Chem. 286:42115-42122. http://dx.doi .org/10.1074/jbc.M111.282830

Whittaker, C.A., and R.O. Hynes. 2002. Distribution and evolution of the von Willebrand/integrin A domains: widely dispersed domains with roles in cell adhesion and elsewhere. Mol. Biol. Cell. 13:3369-3387. http://dx.doi .org/10.1091/mbc.E02-05-0259

Xiao, T., J. Takagi, B.S. Coller, J.H. Wang, and T.A. Springer. 2004. Structural basis for allostery in integrins and binding to fibrinogen-mimetic therapeutics. Nature. 432:59-67. http://dx.doi.org/10.1038/nature02976

Xie, C., J. Zhu, X. Chen, L. Mi, N. Nishida, and T.A. Springer. 2010. Structure of an integrin with an alphaI domain, complement receptor type 4. EMBO J. 29:666-679. http://dx.doi.org/10.1038/emboj.2009.367

Xiong, J.P., T. Stehle, R. Zhang, A. Joachimiak, M. Frech, S.L. Goodman, and M.A. Arnaout. 2002. Crystal structure of the extracellular segment of integrin $\alpha \mathrm{V} \beta 3$ in complex with an Arg-Gly-Asp ligand. Science. 296:151155. http://dx.doi.org/10.1126/science.1069040

Yang, W., M. Shimaoka, A. Salas, J. Takagi, and T.A. Springer. 2004. Intersubunit signal transmission in integrins by a receptor-like interaction with a pull spring. Proc. Natl. Acad. Sci. USA. 101:2906-2911. http://dx.doi .org/10.1073/pnas.0307340101

Yu, Y., J. Zhu, L.Z. Mi, T. Walz, H. Sun, J.-F. Chen, and T.A. Springer. 2012. Structural specializations of $\alpha_{4} \beta_{7}$, an integrin that mediates rolling adhesion. J. Cell Biol. 196:131-146. http://dx.doi.org/10.1083/ jcb.201110023

Zang, Q., and T.A. Springer. 2001. Amino acid residues in the PSI domain and cysteine-rich repeats of the integrin $\beta 2$ subunit that restrain activation of the integrin $\alpha(\mathrm{X}) \beta(2)$. J. Biol. Chem. 276:6922-6929. http://dx.doi .org/10.1074/jbc.M005868200

Zhu, J., B.H. Luo, T. Xiao, C. Zhang, N. Nishida, and T.A. Springer. 2008. Structure of a complete integrin ectodomain in a physiologic resting state and activation and deactivation by applied forces. Mol. Cell. 32:849-861. http://dx.doi.org/10.1016/j.molcel.2008.11.018

Zhu, J., J. Zhu, and T.A. Springer. 2013. Complete integrin headpiece opening in eight steps. J. Cell Biol. 201:1053-1068. http://dx.doi.org/10.1083/ jcb.201212037 